\title{
Modeling Spring-In of L-Shaped Structural Profiles Pultruded at Different Pulling Speeds ${ }^{+}$
}

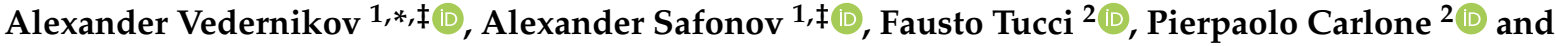 \\ Iskander Akhatov ${ }^{1}[$
}

1 Center for Design, Manufacturing and Materials, Skolkovo Institute of Science and Technology, 30/1 Bolshoi Boulevard, 121205 Moscow, Russia; a.safonov@skoltech.ru (A.S.); i.akhatov@skoltech.ru (I.A.)

2 Department of Industrial Engineering, University of Salerno, Via Giovanni Paolo II, 132-84084 Fisciano, Italy; ftucci@unisa.it (F.T.); pcarlone@unisa.it (P.C.)

* Correspondence: aleksandr.vedernikov@skoltech.ru

+ This paper is an extended version of the conference paper "Analysis of Spring-In Deformation in L-Shaped Profiles Pultruded at Different Pulling Speeds: Mathematical Simulation and Experimental Results". In Proceedings of the ESAFORM 2021 24th International Conference on Material Forming, Liège, Belgique, 14-16 April 2021. https:/ / doi.org/10.25518/esaform21.4743.

$\ddagger \quad$ These authors contributed equally to this work.

check for updates

Citation: Vedernikov, A.; Safonov, A.; Tucci, F.; Carlone, P.; Akhatov, I. Modeling Spring-In of L-Shaped Structural Profiles Pultruded at Different Pulling Speeds. Polymers 2021, 13, 2748. https://doi.org/ $10.3390 /$ polym 13162748

Academic Editor: Francesca Lionetto

Received: 16 July 2021

Accepted: 10 August 2021

Published: 16 August 2021

Publisher's Note: MDPI stays neutral with regard to jurisdictional claims in published maps and institutional affiliations.

Copyright: (c) 2021 by the authors. Licensee MDPI, Basel, Switzerland. This article is an open access article distributed under the terms and conditions of the Creative Commons Attribution (CC BY) license (https:// creativecommons.org/licenses/by/ $4.0 /)$.
Abstract: Cure-induced deformations are inevitable in pultruded composite profiles due to the peculiarities of the pultrusion process and usually require the use of costly shimming operations at the assembly stage for their compensation. Residual stresses formed at the production and assembly stages impair the mechanical performance of pultruded elements. A numerical technique that would allow the prediction and reduction of cure-induced deformations is essential for the optimization of the pultrusion process. This study is aimed at the development of a numerical model that is able to predict spring-in in pultruded L-shaped profiles. The model was developed in the ABAQUS software suite with user subroutines UMAT, FILM, USDFLD, HETVAL, and UEXPAN. The authors used the 2D approach to describe the thermochemical and mechanical behavior via the modified Cure Hardening Instantaneous Linear Elastic (CHILE) model. The developed model was validated in two experiments conducted with a 6-month interval using glass fiber/vinyl ester resin L-shaped profiles manufactured at pulling speeds of 200, 400, and $600 \mathrm{~mm} / \mathrm{min}$. Spring-in predictions obtained with the proposed numerical model fall within the experimental data range. The validated model has allowed authors to establish that the increase in spring-in values observed at higher pulling speeds can be attributed to a higher fraction of uncured material in the composite exiting the die block and the subsequent increase in chemical shrinkage that occurs under unconstrained conditions. This study is the first one to isolate and evaluate the contributions of thermal and chemical shrinkage into spring-in evolution in pultruded profiles. Based on this model, the authors demonstrate the possibility of achieving the same level of spring-in at increased pulling speeds from 200 to $900 \mathrm{~mm} / \mathrm{min}$, either by using a post-die cooling tool or by reducing the chemical shrinkage of the resin. The study provides insight into the factors significantly affecting the spring-in, and it analyzes the methods of spring-in reduction that can be used by scholars to minimize the spring-in in the pultrusion process.

Keywords: pultrusion; spring-in; finite element analysis (FEA); cure behavior; process modeling

\section{Introduction}

Pultrusion is the most efficient process for producing composite structural profiles of constant cross-sections [1-3]. Owing to their high strength-to-weight ratio [4,5], superior corrosion resistance [6,7], and improved durability [8,9], pultruded profiles have been successfully used as structural elements in the fields of bridge construction [10-12], civil [13,14], and architectural engineering [15,16]; marine construction [17,18]; aerospace 
and aviation engineering [19-21]; transportation [22,23]; and energy systems [24]. However, process-induced deformations, such as spring-in (common in curved elements) and warpage (common in flat elements), may result in a certain loss in the economic efficiency of mass production of composite profiles [25]. Spring-in is the primary contributor [26] to the distortion of a profile, which may require costly and time-consuming shimming operations during assembly $[27,28]$. Residual stresses developing during the production and assembly stages are detrimental to the final mechanical performance of a structure $[29,30]$. Thus, the ability to predict, control, and compensate for process-induced deformations is crucial for the effective design and assembly of composite structures [31,32].

The phenomenon of spring-in can be observed in various processes of composite manufacturing, such as autoclave [33-36], resin transfer molding [37-39], vacuum-assisted resin transfer molding [40,41], vacuum bagging [42,43], compression molding [44,45], filament winding [46], microwave curing [47], and pultrusion [48,49]. The main causes of spring-in are the anisotropy of the mechanical properties of a composite [50], [51,52]; chemical $[53,54]$ and thermal $[55,56]$ shrinkage of a material; nonuniform distribution of temperatures [57]; and curing degree [58,59]. The peculiarities of the pultrusion process also contribute to the spring-in because a composite material undergoes all process stages sequentially, i.e., impregnation, heating, polymerization, and cooling. Therefore, the structural properties of the produced profiles depend upon the process conditions used in production [60]. Hence, the creation of numerical models predicting the influence of process conditions on the value of spring-in is a vital problem for the pultrusion process optimization [61-63].

Successful simulation of the pultrusion process requires a model that describes the distribution of temperatures in a composite along with the matrix polymerization process [64-67] and mechanical behavior of a composite during manufacturing [68,69]. To model residual stresses and distortions, Baran et al. [49] applied a 3D approach to solve the thermochemical problem and a 2D approach to explain the mechanical behavior via the Cure Hardening Instantaneous Linear Elastic (CHILE) model. In a follow-up study, they showed that the spring-in value depends on the pulling speed [48]. Wang et al. [70] proposed the numerical model to predict the spring-in and conducted an experiment to compare predictions and experimental results. Predictions were found to be in good agreement with experimental data. It was also found that the contribution of chemical shrinkage into deformations is significantly higher compared to that of thermal expansion. However, those contributions were not quantified.

Despite the lack of studies on spring-in formation in pultruded composites, over the last 30 years, a large number of experimental and numerical studies on the subject have been published in relation to other composite manufacturing processes. Those works studied the influence of cure cycle schedule, thermal shrinkage, and chemical shrinkage on the evolution of cure-induced residual stresses and deformations. Back in 1992, Bogetti and Gillespie [57] proposed a model that is capable of predicting the mechanical characteristics, thermal and chemical strains in resin during polymerization. The study demonstrated the major role of thermal shrinkage and chemical shrinkage in the development of residual stresses and deformations. Jain and Mai [71] have proposed a model based on the modified shell theory, which predicted the evolution of residual stresses and deformations such as spring-in. They have shown that chemical shrinkage, among other factors, has a significant effect on the evolution of residual stresses and shape distortions. Wiersma et al. [53], aiming to build the model capable of accurate prediction of spring-in in L-shaped composites, have considered the thermoelastic model accounting for thermal shrinkage, and the viscoelastic model accounting for irreversible effects occurring during resin polymerization (chemical shrinkage and viscosity evolutions). Subsequently, Radford and Rennick [51] have quantified the contribution of thermoelastic and non-thermoelastic components in spring-in distortion of carbon fiber/epoxy brackets manufactured by the autoclave technique. In 2001, Svanberg and Holmberg [37] studied the influence of the cure cycle on spring-in evolutions in the resin transfer molding process. They distinguished three major factors 
accounting for spring-in, i.e., thermal shrinkage, chemical shrinkage, and frozen-in deformations. While studying the cure quenching phenomenon, Ersoy et al. [72] were able to isolate the contribution of thermal shrinkage (happening before and after vitrification) and of chemical shrinkage to spring-in formation. In 2006, Ruiz and Trochu [73] demonstrated the methodology allowing a researcher to optimize polymerization in a liquid composite molding process by way of minimizing the residual stresses resulting from chemical and thermal shrinkage. The methodology makes it possible to improve the process of resin curing while simultaneously minimizing the process time and residual stresses. In the quenching experiment, Wisnom et al. [50] have shown the development of spring-in at different stages of the cure cycle-initial growth, peak, and reduction during subsequent polymerization. It was shown that at the rubbery state, both thermal and chemical shrinkage affect spring-in evolutions, with the contribution of chemical shrinkage constituting as much as 50\%. In Wisnom et al. [27], the authors proposed and verified experimentally the analytical solution describing the mechanism of spring-in formation due to thermal and chemical shrinkage, taking place between gelation and vitrification of the resin. Hsiao and Gangireddy [41] in 2008 used the vacuum-assisted resin transfer molding (VARTM) process to prove experimentally that the addition of $1.5 \mathrm{wt} \%$ carbon nanofibers to polyester resin allows a spring-in reduction by as much as $73 \%$ through a reduction of deformations caused by thermal and chemical shrinkage. The analytical solution and the 3D FEA model proposed confirm the experimental results and predict a complete elimination of spring-in at $10 \mathrm{wt} \%$ of carbon nanofibers. Li et al. [47] have shown that it is possible to significantly reduce the cure-induced strains in carbon fiber-reinforced bismaleimide composites by replacing conventional thermal curing process for the microwave one and to achieve spring-in reduction in the L-shaped structure by as much as $1.2^{\circ}$. Subsequently, Kravchenko et al. [74] conducted the experimental and numerical study of deflection in bi-lamina strips caused by thermal and chemical shrinkage, occurring at various stages of the cure cycle. Takagaki et al. [75] in 2017 used Fiber Bragg Grating (FBG) sensors to experimentally measure through-thickness normal and shear strains. The results obtained were used to analyze the curing process and the development of spring-in in the L-shaped carbon-fiber-reinforced polymer (CFRP) part at different stages of the cure process, which are associated with chemical and thermal shrinkage. Nawab et al. [76] showed numerically the evolution of spring-in in a carbon/epoxy woven composite bracket at different stages of the cure cycle and subsequent cooling, and they established that the contribution of thermal shrinkage constituted $81 \%$, while that of chemical shrinkage during curing constituted only $19 \%$. Hu et al. [77] demonstrated an in situ method to monitor gelation and determine the evolution of effective chemical shrinkage during polymerization, using the FBG sensors. The authors have manufactured the C-shape composite specimens and compared the spring-in values predicted with the use of the thermal model (accounting only for the thermal shrinkage) and of Rennick's model [51]. Three methods were used to measure the chemical shrinkage-by bi-material strip, by Thermal Mechanical Analysis, and by FBG sensors - with the latter producing the most reliable results. Exner et al. [78] have shown experimentally that the addition of aluminum oxide nanoparticles in the amount of at least $5 \mathrm{wt} \%$ reduces chemical and thermal shrinkage, resulting in a reduction of spring-in in vacuum-infused CFRP L-shaped composites. In 2019, Groh et al. [79] in the experimental study of RTM-fabricated L-shaped CFRP composites based on Fast Curing Epoxy Resin have shown the absence of relation between the spring-in and the cooling rate. Subsequently, Qiao and Yao [80] proposed the 3D numerical model and calculated the contributions of thermal shrinkage, chemical shrinkage, and of tool-part interaction to the spring-in in the L-shaped structure. It was found that the contribution of thermal shrinkage is almost independent of part thickness, and that of the chemical shrinkage reduces with increase in part thickness. It was also found that the spring-in caused by chemical shrinkage is higher compared to that caused by thermal shrinkage. Shaker et al. [81] through the addition of $5 \%$ of silica microparticle fillers were able to reduce the coefficient of thermal expansion of resin and, as a result, to reduce the spring-in 
in glass/vinyl ester L-shaped composite parts by as much as $65 \%$, from $1.807^{\circ}$ to $0.632^{\circ}$. Recently, Struzziero et al. [82] conducted the experimental and numerical study of the residual stress and warpage deformations during cure in laminates produced by VARTM. The authors used the multi-objective optimization and proposed the method of reducing the warpage by as much as $10 \%$ and manufacturing time by $33 \%$.

The majority of studies on the subject discussed here are devoted to the composite manufacturing processes other than pultrusion. Hence, the insights from those studies cannot be fully applied when studying the pultrusion process, due to the unique features of pultrusion as the manufacturing process. However, the few existing studies of spring-in in pultruded composites fail to explore the subject comprehensively. For example, these studies do not provide experimental validation of numerical models at various pulling speeds. Moreover, no thorough analysis has been conducted on the reasons for spring-in increase at higher pulling speeds. In addition, the authors failed to separate and evaluate the contributions from thermal and chemical shrinkage to the final value of spring-in during the polymerization and cooling phases. This study is aimed at the analysis of thermal and chemical shrinkage influence on the evolutions of spring-in in L-shaped profiles taking place at different pulling speeds. This study also aims to investigate the ways to minimize the spring-in through the use of a post-die cooling tool or by reducing the chemical shrinkage of the resin. The outcomes of this study can be used by researchers to minimize spring-in deformations occurring during pultrusion.

This paper presents a numerical and experimental study of the influence of pulling speed on the value of spring-in in L-shaped structural pultruded profiles of $75 \mathrm{~mm} \times 75 \mathrm{~mm}$ $\times 6 \mathrm{~mm}$. The pultrusion of vinyl ester-based profiles reinforced with unidirectional glass fiber rovings and fabrics was carried out. Two pultrusion experiments were performed, with a 6-month interval. The spring-in in pultruded profiles was measured on the same day of manufacture after the profiles got cooled to room temperature. A numerical simulation of the pultrusion process at different pulling speeds was performed using a 2D approach to thermochemical and mechanical behavior via the modified CHILE model. The results demonstrate good correlation between numerical predictions and experimental values of spring-in. The study also evaluated the contribution of each mechanism to the formation of spring-in. The results show that the largest contribution to spring-in comes from the chemical shrinkage of the matrix after the exit from the die block and the thermal shrinkage of the composite when cooling to the glass transition temperature. Numerical simulation results were used to analyze the possibility of reducing the spring-in with the help of a post-die cooling tool or by reducing the chemical shrinkage of the resin.

\section{Materials and Methods}

\subsection{Pultrusion Manufacturing}

The profiles used for the experiments were manufactured using the Pultrex Px500-6T pultrusion machine (Pultrex, Lawford, UK) at the Laboratory of Composite Materials and Structures of the Center for Design, Manufacturing and Materials (Skolkovo Institute of Science and Technology, Moscow, Russia) (Figure 1a). Two pultrusion experiments with $75 \mathrm{~mm} \times 75 \mathrm{~mm} \times 6 \mathrm{~mm}$ L-shaped structural profiles (Figure 1c) have been conducted with a 6-month interval. In total, 104 threads of E-glass unidirectional rovings PS 2100 (Owens Corning Composite Materials, Toledo, OH, USA) with a linear density of 9600 TEX $(9600 \mathrm{~g} / 1000 \mathrm{~m})$, and two layers of E-glass fabric LT 0600/S 300/06H 01/125 GUS (Owens Corning Composite Materials, Toledo, OH, USA) with a surface density of $900 \mathrm{~g} / \mathrm{m}^{2}$ were utilized as reinforcement. The matrix was composed of Atlac 430 vinyl ester resin (DSM Composite Resins AG, Schaffhausen, Switzerland) with the following additives: Triganox C (Akzo Nobel Polymer Chemicals B.V., Amsterdam, The Netherlands), Perkadox 16 (Akzo Nobel Polymer Chemicals B.V., Amsterdam, The Netherlands), BYK-A555 (BYK Additives \& Instruments, Wesel, Germany), and zinc stearate (Baerlocher $\mathrm{GmbH}$, Unterschleißheim, Germany). To fabricate the profiles, the $600 \mathrm{~mm}$-long steel die block was used, with four $350 \mathrm{~mm}$-long heating platens installed by pairs at the top and the bottom of the die block 
along the pulling axis. In order to control the die block temperature, two thermocouples were installed within the body of the die block. The allowable temperature range was $145 \pm 10{ }^{\circ} \mathrm{C}$. In total, six $1.5 \mathrm{~m}$-long profiles were manufactured in two experiments at pulling speeds of 200, 400, and $600 \mathrm{~mm} / \mathrm{min}$ (see Figure $1 \mathrm{~b}$ ). The spring-in angle was measured $3 \mathrm{~h}$ after the pultrusion experiment, after the profiles had cooled to the ambient temperature. To measure the spring-in, a set of thin metallic strips (thicknesses of 0.1-1 mm) and a calibrated L-shaped right-angled tool to ensure the correctness of $90^{\circ}$ angle measurements were used [83]. The required number of metallic strips were placed in the gap between the leg of the profile and angle tool, and the total thickness of the strips $\left(t_{s}\right)$ was registered (Figure 1d). The angular value of spring-in $(\varphi)$ is determined based on the size of the profile legs $\left(\mathrm{L}_{\mathrm{w}}=62 \mathrm{~mm}\right)$ and the measured total thickness of metallic strips inserted into the gap $\left(t_{s}\right)[60]$ :

$$
\varphi=\frac{180^{\circ}}{\pi} \arctan \left(\mathrm{t}_{\mathrm{s}} / \mathrm{L}_{\mathrm{w}}\right)
$$

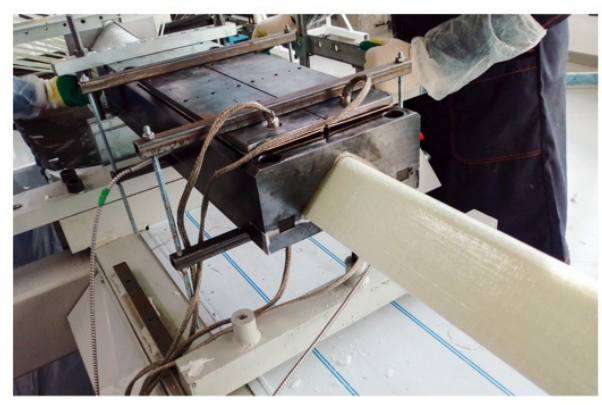

(a)

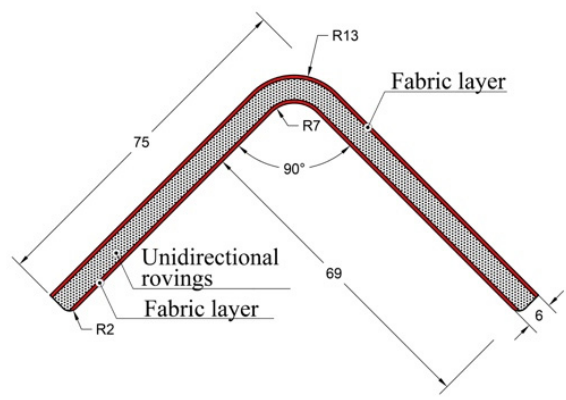

(c)

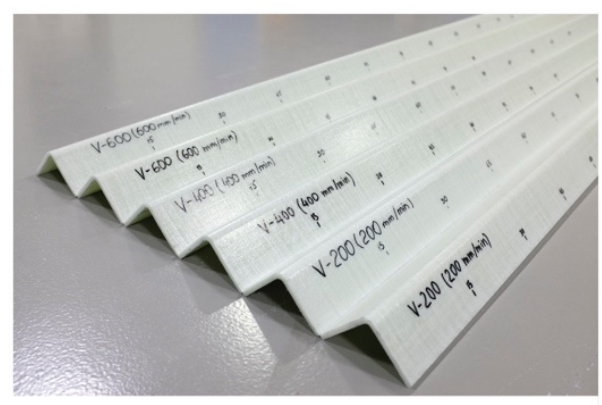

(b)



(d)

Figure 1. Pultrusion process setup: (a) Pultrusion of an L-shaped profile; (b) L-shaped profiles pultruded at pulling speeds of 200,400, and $600 \mathrm{~mm} / \mathrm{min}$; (c) The cross-section of a $75 \mathrm{~mm} \times 75 \mathrm{~mm}$ $\times 6 \mathrm{~mm}$ L-shaped pultruded profile and the position of the unidirectional rovings and fabric layers; (d) Schematic representation of the spring-in measurement process.

The accuracy of this spring-in measurement method constituted $\pm 0.09^{\circ}$. The average of all values measured at several sections along the length of the profile was taken as the final value of spring-in [84].

\subsection{Modeling}

In this section, a thermomechanical initial-boundary value problem (IBVP) is discussed. A numerical modeling tool is used to predict the response of a body to applied temperature loads. This can be achieved by solving the given IBVP problem. A more detailed description of this IBVP statement can be found in Zocher et al. [85] and in Svanberg and Holmberg [56]. Two problems should be solved in resin polymerization modeling, namely, the heat transfer problem (Section 2.2.1) and the mechanical problem (Section 2.2.2). As the properties of resin and, therefore, of composite material depend on the temperature, in order to solve this IBVP, the distribution of temperature and polymerization degree was 
modeled with Equations (2)-(8) of the 2D thermochemical model presented in Section 2.2.1. Then, based on results obtained and using the equations presented in Section 2.2.2, it was possible to determine the cure- and temperature-dependent Young's modulus (Equations (9) and (10)), bulk modulus (Equations (11) and (12)), and Poisson's ratio (Equation (13)) of the resin. The given mechanical properties of the resin were used further to calculate mechanical properties of a composite, based on the Self-Consistent Field Micromechanics (SCFM) approach [86,87]. Finally, the obtained mechanical properties of a composite are used to determine the stress-strain state in the composite. A more detailed description of the mechanical problem statement of process-induced residual stresses and distortions can be found in Baran et al. [49]. The novelty of the mechanical problem presented here is in the more accurate CHILE model that uses seven regions to describe changes in Young's modulus of resin, and it accounts for changes in Poisson's ratio of the matrix during phase transitions.

Earlier, it was shown that axial conduction can be neglected when solving the temperature problem [88]. In addition, no significant differences were found in the distributions of stresses and displacements in the transverse direction, which were obtained in $2 \mathrm{D}$ and 3D simulations of mechanical behavior [89]. Thus, to accelerate computations, a twodimensional model was used to solve the thermochemical and mechanical problems in this study. However, these assumptions may result in overestimated values of thermal peak. In addition, the 2D approach makes it impossible to account for stresses, occurring along the longitudinal axis of the profile and causing additional shape distortions in the pulling direction. Nevertheless, further, it will be shown that these assumptions are reasonable and will not result in large discrepancy between predicted and experimental spring-in data.

\subsubsection{D Thermal Model}

A steady-state pultrusion process with a pulling speed of $u$ is considered. By disregarding the heat conduction along the length of the composite profile, the heat transfer equation in a Lagrangian (material) frame of reference can be expressed as follows [88]:

$$
\mathrm{C}_{\mathrm{p}_{-} \text {comp }}(\mathrm{T}) \rho_{\text {comp }} \frac{\partial \mathrm{T}}{\partial \mathrm{t}}=\mathrm{k}_{\text {comp }} \frac{\partial^{2} \mathrm{~T}}{\partial \mathrm{x}^{2}}+\mathrm{k}_{\text {comp }} \frac{\partial^{2} \mathrm{~T}}{\partial \mathrm{y}^{2}}+\mathrm{q},
$$

where $\mathrm{x}$ and $\mathrm{y}$ are the coordinates of a cross-section of the composite profile, $\mathrm{T}$ is instantaneous temperature, $\mathrm{C}_{\mathrm{p}_{-} \text {comp }}(\mathrm{T})$ is the temperature-dependent heat capacity of a composite material, $\rho_{\text {comp }}$ is the composite density, $\mathrm{k}_{\text {comp }}$ is the thermal conductivity of the composite in the cross-sectional plane, and $\mathrm{q}$ is the heat released due to the exothermic reaction in a polymer matrix. As the heat equation is expressed in the Lagrangian (material) frame of reference, the pulling speed (u), absent in Equation (2), affects the boundary condition equations (Equations (3) and (4)), corresponding to the position of the composite profile cross-section inside or outside the die, respectively:

$$
\begin{aligned}
& \left.\mathrm{k}_{\text {comp }} \frac{\partial \mathrm{T}}{\partial \mathrm{n}}\right|_{\Gamma}=-\mathrm{h}_{\text {die }}\left(\mathrm{T}-\mathrm{T}_{\text {die }}(\mathrm{z})\right) \text { at } \mathrm{z}=\mathrm{ut}<\mathrm{L}_{\text {die }}, \\
& \left.\mathrm{k}_{\text {comp }} \frac{\partial \mathrm{T}}{\partial \mathrm{n}}\right|_{\Gamma}=-\mathrm{h}_{\mathrm{air}}\left(\mathrm{T}-\mathrm{T}_{\mathrm{amb}}(\mathrm{z})\right) \text { at } \mathrm{z}=\mathrm{ut} \geq \mathrm{L}_{\text {die }},
\end{aligned}
$$

where $\Gamma$ is the surface of the profile, $h_{d i e}$ is the coefficient of convective heat transfer between the die block and the profile, $\mathrm{h}_{\mathrm{air}}$ is the coefficient of convective heat transfer between the air and the profile after exiting the die block, $\mathrm{T}_{\text {die }}$ is the temperature of the die block, changing along the pulling direction $\mathrm{z}$, and $\mathrm{T}_{\mathrm{amb}}$ is the ambient temperature.

Assuming the temperature of the composite at the die block entrance, $T_{i n}$, to be uniform over the entire cross-section, it can be expressed as follows:

$$
\left.\mathrm{T}\right|_{\mathrm{t}=0}=\mathrm{T}_{\mathrm{in}}
$$


The internal heat released due to the exothermic reaction of the resin (q) during polymerization can be expressed as:

$$
\mathrm{q}=\left(1-\mathrm{V}_{\mathrm{f}}\right) \rho_{\mathrm{R}} \mathrm{H}_{\mathrm{tot}} \frac{\mathrm{d} \alpha}{\mathrm{dt}},
$$

where $V_{f}$ is the volume fraction of reinforcement in a composite, $\rho_{r}$ is the resin density, $\mathrm{H}_{\text {tot }}$ is total heat released during curing, and $\frac{\mathrm{d} \alpha}{\mathrm{dt}}$ is the resin curing rate.

To describe the rate of resin polymerization the equation of the $n$-th order, an autocatalytic reaction is used [90]:

$$
\frac{\mathrm{d} \alpha}{\mathrm{dt}}=\mathrm{A}_{0} \mathrm{e}^{-\frac{\mathrm{E}_{a}}{\mathrm{R}(\mathrm{T}+27.15)}}(1-\alpha)^{\mathrm{n}}\left(1+\mathrm{K}_{\mathrm{cat}} \alpha\right),
$$

where $A_{0}$ is the pre-exponential coefficient, $E_{a}$ is the activation energy, $R$ is the universal gas constant, $\mathrm{T}$ is the instantaneous temperature of the resin in degrees Celsius, $\mathrm{n}$ is the order of reaction, and $\mathrm{K}_{\mathrm{cat}}$ is the activation constant.

It is assumed that preheating the material before the entrance into the die block will not result in its polymerization; hence, the degree of polymerization at the die block entrance is taken to be zero:

$$
\left.\alpha\right|_{\mathrm{t}=0}=0 \text {. }
$$

\subsubsection{D Mechanical Model}

It is assumed that resin starts gaining in Young's modulus $\left(\mathrm{E}_{\mathrm{r}}\right)$ and becomes able to sustain stresses after the gelation point $\left(\alpha_{\mathrm{gel}}=0.6\right)$. To account for changes in the Young's modulus of the resin $\left(\mathrm{E}_{\mathrm{r}}\right)$ during the polymerization process and to describe the mechanical behavior of the resin, the CHILE model is used in its modified form [91]:

$$
\mathrm{E}_{\mathrm{r}}=\left\{\begin{aligned}
\mathrm{E}_{\mathrm{r}}^{0}, & \mathrm{~T}^{*} \leq \mathrm{T}_{\mathrm{C} 1} \\
\mathrm{E}_{\mathrm{r}}^{0}+\frac{\mathrm{T}^{*}-\mathrm{T}_{\mathrm{C} 1}}{\mathrm{~T}_{\mathrm{C} 2}-\mathrm{T}_{\mathrm{C} 1}}\left(\mathrm{E}_{\mathrm{r}}^{1}-\mathrm{E}_{\mathrm{r}}^{0}\right), & \mathrm{T}_{\mathrm{C} 1}<\mathrm{T}^{*}<\mathrm{T}_{\mathrm{C} 2} \\
\mathrm{E}_{\mathrm{r}}^{1}+\frac{\mathrm{T}^{*}-\mathrm{T}_{\mathrm{C} 2}}{\mathrm{~T}_{\mathrm{C} 3}-\mathrm{T}_{\mathrm{C} 2}}\left(\mathrm{E}_{\mathrm{r}}^{2}-\mathrm{E}_{\mathrm{r}}^{1}\right), & \mathrm{T}_{\mathrm{C} 2}<\mathrm{T}^{*}<\mathrm{T}_{\mathrm{C} 3} \\
\mathrm{E}_{\mathrm{r}}^{2}+\frac{\mathrm{T}^{*}-\mathrm{T}_{\mathrm{C} 3}}{\mathrm{~T}_{\mathrm{C} 4}-\mathrm{T}_{\mathrm{C} 3}}\left(\mathrm{E}_{\mathrm{r}}^{3}-\mathrm{E}_{\mathrm{r}}^{2}\right), & \mathrm{T}_{\mathrm{C} 3}<\mathrm{T}^{*}<\mathrm{T}_{\mathrm{C} 4} \\
\mathrm{E}_{\mathrm{r}}^{3}+\frac{\mathrm{T}^{*}-\mathrm{T}_{\mathrm{C} 4}}{\mathrm{~T}_{\mathrm{C} 5}-\mathrm{T}_{\mathrm{C} 4}}\left(\mathrm{E}_{\mathrm{r}}^{4}-\mathrm{E}_{\mathrm{r}}^{3}\right), & \mathrm{T}_{\mathrm{C} 4}<\mathrm{T}^{*}<\mathrm{T}_{\mathrm{C} 5} \\
\mathrm{E}_{\mathrm{r}}^{4}+\frac{\mathrm{T}^{*}-\mathrm{T}_{\mathrm{C} 5}}{\mathrm{~T}_{\mathrm{C} 6}-\mathrm{T}_{\mathrm{C} 5}}\left(\mathrm{E}_{\mathrm{r}}^{\infty}-\mathrm{E}_{\mathrm{r}}^{4}\right), & \mathrm{T}_{\mathrm{C} 5}<\mathrm{T}^{*}<\mathrm{T}_{\mathrm{C} 6} \\
\mathrm{E}_{\mathrm{r}}^{\infty}, & \mathrm{T}_{\mathrm{C} 6} \leq \mathrm{T}^{*}
\end{aligned}\right.
$$

where $T^{*}=T_{g}(\alpha)-T$ is the difference between the instantaneous glass transition temperature $\left(\mathrm{T}_{\mathrm{g}}\right)$ and the instantaneous temperature $(\mathrm{T})$ of a resin in degrees Celsius; $\mathrm{T}_{\mathrm{C} 1}, \mathrm{~T}_{\mathrm{C} 2}$, $\mathrm{T}_{\mathrm{C} 3}, \mathrm{~T}_{\mathrm{C} 4}, \mathrm{~T}_{\mathrm{C} 5}$, and $\mathrm{T}_{\mathrm{C} 6}$ are the critical temperatures in degrees Celsius, and $\mathrm{E}_{\mathrm{r}}^{0}, \mathrm{E}_{\mathrm{r}}^{1}, \mathrm{E}_{\mathrm{r}}^{2}, \mathrm{E}_{\mathrm{r}}^{3}$, $\mathrm{E}_{\mathrm{r}}^{4}$, and $\mathrm{E}_{\mathrm{r}}^{\infty}$ are the corresponding elastic moduli. $\mathrm{T}_{\mathrm{g}}(\alpha)$ is the glass transition temperature depending on the degree of cure, which is expressed as follows [92,93]:

$$
\mathrm{T}_{\mathrm{g}}(\alpha)=\mathrm{T}_{\mathrm{g} 0}+\left(\mathrm{T}_{\mathrm{g} \infty}-\mathrm{T}_{\mathrm{g} 0}\right) \frac{\lambda \alpha}{1-(1-\lambda) \alpha^{\prime}},
$$

where $\mathrm{T}_{\mathrm{g} 0}$ is the glass transition temperature of the uncured resin $(\alpha=0), \mathrm{T}_{\mathrm{g} \infty}$ is that of the fully cured resin $(\alpha=1)$, and $\lambda$ is the material parameter.

To account for the changes in Poisson's ratio during phase transitions, it should be noted that the bulk modulus of resin has the same order of magnitude in both rubberlike and glassy states [94]. According to Svanberg [56], the bulk modulus of the matrix 
decreases 2.5 times during the transition from the glassy $\left(\mathrm{K}_{\mathrm{r}}^{\infty}\right)$ to the rubber-like state $\left(\mathrm{K}_{\mathrm{r}}^{0}\right)$. By determining the bulk modulus of the matrix in glassy and rubber-like states based on the linear elastic theory (Equation (11)) [94], the instantaneous bulk modulus of the matrix $\left(\mathrm{K}_{\mathrm{r}}\right)$ and the corresponding Poisson's ratio $\left(v_{\mathrm{r}}\right)$ can be determined using Equations (12) and (13), accordingly:

$$
\begin{gathered}
\mathrm{K}_{\mathrm{r}}^{\infty}=\frac{\mathrm{E}_{\mathrm{r}}^{\infty}}{3\left(1-2 v_{\mathrm{r}}^{\infty}\right)^{\prime}} \\
\mathrm{K}_{\mathrm{r}}\left(\mathrm{E}_{\mathrm{r}}\right)=\mathrm{K}_{\mathrm{r}}^{0}+\left(\mathrm{K}_{\mathrm{r}}^{\infty}-\mathrm{K}_{\mathrm{r}}^{0}\right) \frac{\mathrm{E}_{\mathrm{r}}-\mathrm{E}_{\mathrm{r}}^{0}}{\mathrm{E}_{\mathrm{r}}^{\infty}-\mathrm{E}_{\mathrm{r}}^{0}} \\
v_{\mathrm{r}}\left(\mathrm{E}_{\mathrm{r}}\right)=\frac{3 \mathrm{~K}_{\mathrm{r}}-\mathrm{E}_{\mathrm{r}}}{6 \mathrm{~K}_{\mathrm{r}}} .
\end{gathered}
$$

Then, the instantaneous mechanical properties of the resin are used to compute effective mechanical properties of the composite, using the Self-Consistent Field Micromechanics (SCFM) approach $[86,87]$. Thus, the obtained effective mechanical properties of a composite are subsequently applied to determine the stress-strain state in the composite [49]. The analytical relationships used to predict the effective mechanical properties and stress-strain state in the composite are presented in Supplementary Materials.

\subsubsection{Finite Element Modeling}

The IBVP described earlier is solved by means of finite element analysis in ABAQUS FEA software suite (6.14, Dassault Systèmes SE, Vélizy-Villacoublay, France) [95]. Displacements and stresses are computed using the incremental linear elastic approach [49]. The following subroutines are used in the simulations: UMAT, FILM, USDFLD, HETVAL, and UEXPAN. The UMAT subroutine is used to calculate thermal and chemical deformations; to compute the mechanical properties of a composite, using the Self-Consistent Field Micromechanics (SCFM) approach; and to describe constitutive mechanical behavior of a composite. The FILM subroutine is used to assign temperature loads and to describe convective heat transfer between the composite and an environment, both inside and outside the die block. The USDFLD is used to define the cure degree at each point of material as a function of time and temperature; HETVAL is used to specify internal heat generation due to exothermic reaction in a polymer matrix during heat transfer analysis; and UEXPAN is used to add non-mechanical strains (thermal and chemical) to mechanical ones to obtain the total strain tensor. In order to build the model, the 4-node plane strain thermally coupled quadrilateral CPE4RT type elements are used. As the profile section is symmetric, only half of the model, consisting of 1056 elements, is used in simulations. Simulations were performed with different numbers of finite elements in order to calculate the spring-in, using the model described in Section 2.2. It was noted that increasing the number of finite elements (starting from 1056 elements), while significantly increasing the simulation time, did not lead to noticeable differences in the final value of spring-in. That is, the refinement of the mesh does not provide significant changes in simulation results.

The numerical model developed for this study uses four different material types (Figure 2c) corresponding to different types of reinforcement used in the pultrusion of L-shaped profiles (Figure 2a,b) as follows: (1) Material_1, transversely isotropic, with the axis of anisotropy oriented along the pulling direction to model the roving; (2) Material_2, transversely isotropic, with the axis of anisotropy oriented along the pulling direction to model the internal layer of fabric; (3) Material_3, with the axis of anisotropy lying within the cross-section plane and oriented parallel to the leg of the L-shaped profile to model the core layer of fabric; and (4) Material_4, transversely isotropic with axis of anisotropy oriented perpendicular to the lay-up plane to model the mat glued to the fabric. Material_1 represents the unidirectional reinforcement used to fabricate L-shaped profiles. Three materials were utilized to model the fabric material used to fabricate L-shaped profiles: Material_2, Material_3, and Material_4. In ABAQUS, Material_2 and Material_3 (representing the unidirectional reinforcement) were assigned the same material properties 
but with different reinforcement orientation along the direction of pultrusion and in the cross-sectional plane, respectively. Material_4 represents the material with randomly oriented reinforcement in the lay-up plane.

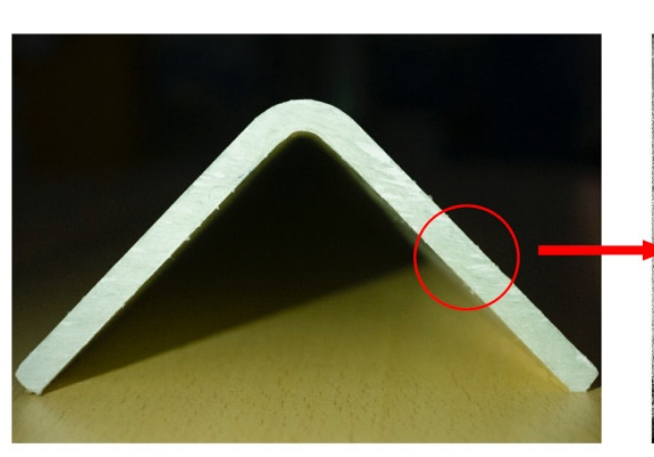

(a)

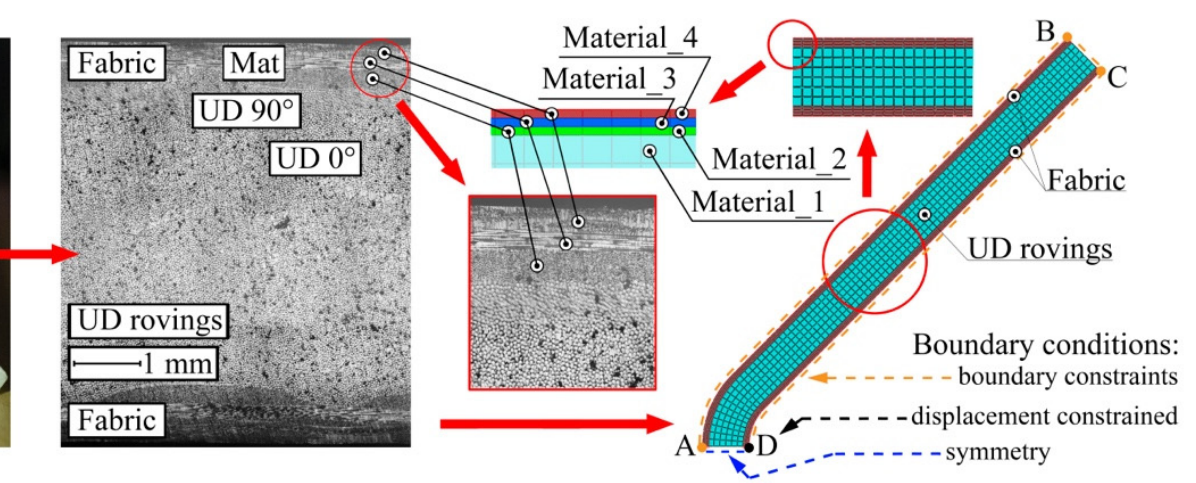

(b)

(c)

Figure 2. Building the numerical model of a pultruded L-shaped profile: (a) Cross-section of the L-shaped pultruded profile;

(b) Microphotograph of the cross-section of the pultruded profile showing the arrangement of UD rovings and fabric layers;

(c) Numerical model of the L-shaped pultruded profile built-in ABAQUS software.

For the AD edge, the symmetrical boundary conditions are set (blue dashed line in Figure 2c). The boundary constraints used to simulate the internal surface of the die block prohibit any motion at the outer perimeter of the profile inside the die block region (the ABCD segment, orange dashed line in Figure 2c). The boundary constraints are deactivated after the die block exit. In addition, any displacements of a composite at the point $\mathrm{D}$ are constrained (orange dashed line in Figure 2c).

Furthermore, the spring-in reduction method that provides for the use of a rigid post-die cooling tool was simulated. The length of the post-die cooling tool constitutes $1 / 3$ of the length of the die block $\left(\mathrm{L}_{\text {die }} / 3\right)$. It is assumed that the post-die cooling tool has constant temperature equal to the ambient temperature $\left(\mathrm{T}_{\mathrm{amb}}\right)$ and is installed immediately after the end of the heated die block. The geometry and positions of the heated die block and post-die cooling tool are shown in Figure 3.

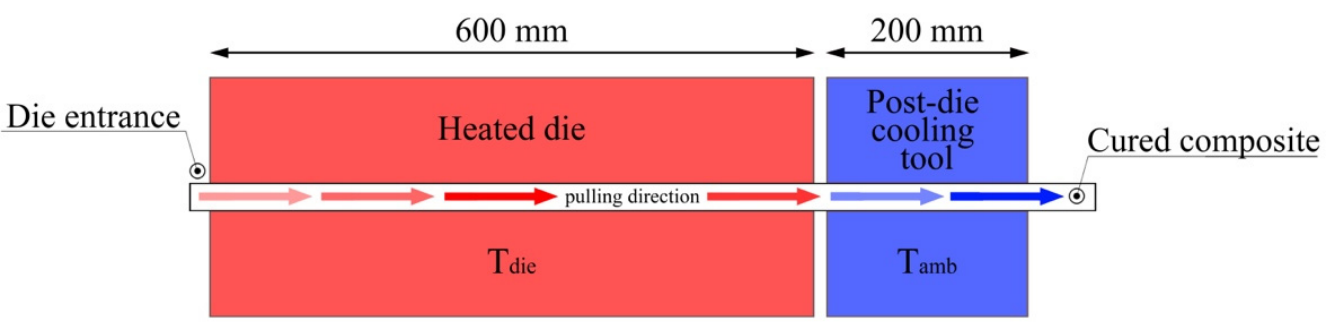

Figure 3. Geometry and position of the heated die and post-die cooling tool.

\subsection{Experimental Methods to Determine Model Parameters}

To determine the parameters of the model, a series of thermomechanical and thermophysical tests were conducted. Test specimens were cut from plates of cured vinyl ester resin. The plates were polymerized in a laboratory vacuum drying oven XF050 (France Etuves, Chelles, France) under the following procedure: $1.5 \mathrm{~h}$ at $120^{\circ} \mathrm{C}, 30 \mathrm{~min}$ at $150{ }^{\circ} \mathrm{C}$, followed by natural cooling for $12 \mathrm{~h}$. An Shtalmark M1-912 M/2 (Rusintermash Ltd., Pushkino, Russia) CNC milling machine was used to cut specimens from polymerized plates. The glass transition temperature and temperature dependence of the storage and loss moduli of cured resin were determined using Dynamic Mechanical Analysis (DMA) following the ISO 6721-1:2011 procedure [96], in the 3-point bending mode, with a Q800 DMA analyzer (TA Instruments Inc., New Castle, DE, USA). Measurements were taken in the temperature range of $30-170^{\circ} \mathrm{C}$, with a heating ramp of $5^{\circ} \mathrm{C} / \mathrm{min}$, an oscil- 
lation frequency of $1 \mathrm{~Hz}$, and an amplitude of $60 \mu \mathrm{m}$. A DSC 204 differential scanning calorimeter (NETZSCH-Gerätebau GmbH, Selb, Germany) was used to measure the heat capacity of the cured resin. Measurements were taken following the procedure specified in ISO 11357-4:2005 [97], within the temperature range of $20-100^{\circ} \mathrm{C}$, with a heating ramp of $10{ }^{\circ} \mathrm{C} / \mathrm{min}$. The thermal conductivity of the cured resin was measured according to the ISO 22007-4:2008 procedure [98] in the temperature range of $20-100{ }^{\circ} \mathrm{C}$, using an LFA 457 MicroFlash laser flash apparatus (NETZSCH-Gerätebau GmbH, Selb, Germany). To determine the coefficient of thermal expansion (CTE) of cured resin, a TMA 402F thermomechanical analyzer (NETZSCH-Gerätebau $\mathrm{GmbH}$, Selb, Germany) was used, following the ISO 11359-2:1999 procedure [99], at a temperature of $20^{\circ} \mathrm{C}$. The density of the cured resin was determined by hydrostatic weighing of four samples of $25 \mathrm{~mm} \times 25 \mathrm{~mm} \times 2 \mathrm{~mm}$, using HTR-220CE electronic laboratory scales (Shinko Vibra, Tokyo, Japan).

\section{Results}

\subsection{Model Parameters}

Figure 4 shows the determined parameters of the model: Young's modulus of resin (Figure $4 a$ ) and heat capacity of resin (Figure $4 b$ ). The least squares method was used to determine the temperature-dependent specific heat and the constants of the modified CHILE model, based on experimental data. In addition, based on DMA data, the value of $\mathrm{T}_{\mathrm{g} \infty}$ was found, constituting $\mathrm{T}_{\mathrm{g} \infty}=120.4^{\circ} \mathrm{C}$. The heat capacity demonstrates linear temperature dependence of the form $\mathrm{C}_{\mathrm{p} \_r}(\mathrm{~T})=(5.1 \cdot \mathrm{T}+1080) \mathrm{J} /\left(\mathrm{kg} \cdot{ }^{\circ} \mathrm{C}\right)$. Thermal conductivity measurements conducted within the range of $20-100{ }^{\circ} \mathrm{C}$ show that the difference in thermal conductivity values does not exceed $2 \%$. That is why thermal conductivity is assumed to be constant and equal to the average experimental value of $\mathrm{k}_{\mathrm{r}}=0.178 \mathrm{~W} /\left(\mathrm{m} \cdot{ }^{\circ} \mathrm{C}\right)$. The coefficient of thermal expansion measured at the temperature of $20^{\circ} \mathrm{C}$ constituted $\alpha_{\mathrm{r}}^{\infty}=60 \cdot \times 10^{-6}{ }^{\circ} \mathrm{C}^{-1}$. The density of resin constitutes $\rho_{\mathrm{r}}=1140 \mathrm{~kg} / \mathrm{m}^{3}$. All measured parameters of the model are given in Table A1.

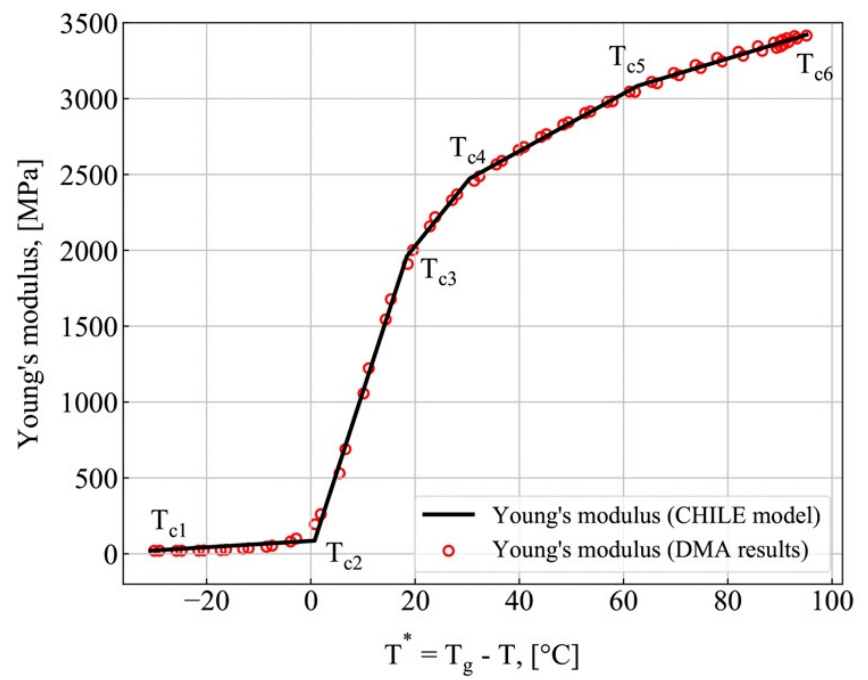

(a)



(b)

Figure 4. Model parameters measurements: (a) Young's modulus (DMA measurements vs. CHILE model predictions); (b) Heat capacity (DSC measurements vs. predictions obtained with the linear approximation).

\subsection{Finite Element Modeling Results}

The spring-in values were obtained by simulating the pultrusion of the L-shaped profile at pulling speeds of 200, 400, and $600 \mathrm{~mm} / \mathrm{min}$. The results were compared with the values obtained during the two pultrusion experiments. Then, numerical simulations were conducted to analyze the influence of pulling speed increase and of changes in Poisson's ratio during phase transitions (according to Equation (13)) on the value of spring- 
in. Furthermore, the efficiency of methods of spring-in reduction was analyzed by using a post-die cooling tool or by reducing the chemical shrinkage of the matrix.

Table A1 lists the model parameters used in the computations, together with the information on the source of the data. A key feature of the model discussed here is that it uses experimentally determined values of density, temperature-dependent heat capacity, thermal conductivity, CTE, and mechanical properties of the resin (see Section 2). The values of density, heat capacity, and thermal conductivity of glass-fiber reinforcement were taken from [49], the mechanical properties of glass-fiber reinforcement were taken from [57], the kinetic constants of resin polymerization were taken from [90], and resin properties were taken from $[49,56,100]$. To determine the properties of the composite layers (Material_1, Material_2, Material_3, Material_4), the following analytical relationships were used: the density and heat capacity were determined as described in [88]; thermal conductivity were determined as described in [101]; the mechanical properties of Material_1, Material_2, and Material_3 were determined as described in [57]; and those of Material_4 were determined as described in [102]. The mentioned relationships and data for each Material_1, Material_2, Material_3, and Material_4 can be found in the Supplementary Materials.

In addition, at the outer perimeter of the profile, the boundary conditions of thermal contact with the ambient air, based on the given coefficient of convective heat transfer, were imposed. For the profile inside the die block, very high values of the convective heat transfer coefficient $\left(\mathrm{h}_{\mathrm{die}}=5000 \mathrm{~W} /\left(\mathrm{m}^{2} \cdot{ }^{\circ} \mathrm{C}\right)\right)$ were assigned to simulate perfect thermal contact with the die block. To simulate the thermal contact of the profile with the ambient air after the die block exit, the convective heat transfer coefficient of $h_{\text {air }}=9 \mathrm{~W} /\left(\mathrm{m}^{2} \cdot{ }^{\circ} \mathrm{C}\right)$ and the ambient temperature of $\mathrm{T}_{\mathrm{amb}}=18^{\circ} \mathrm{C}$ were assigned.

Figures 5 and 6 show the spring-in simulation results obtained at various pulling speeds from 100 to $1000 \mathrm{~mm} / \mathrm{min}$. Figure 7 shows the distributions of temperature and degree of polymerization obtained at pulling speeds of 200,600 , and $1000 \mathrm{~mm} / \mathrm{min}$. Figure 5 shows the simulation results obtained with the model described in Section 2. Figure 5a shows the final spring-in values obtained at different pulling speeds, together with the experimental values of spring-in for pulling speeds of 200,400 , and $600 \mathrm{~mm} / \mathrm{min}$. At these speeds, the predicted values fall between corresponding experimental data points (see Table 1). For the pulling speed of $200 \mathrm{~mm} / \mathrm{min}$, the predicted value constitutes $1.15^{\circ}$ and is located between $0.97^{\circ}$ (obtained in Experiment 1) and $1.16^{\circ}$ (Experiment 2). For the pulling speed of $400 \mathrm{~mm} / \mathrm{min}$, the predicted value of $1.40^{\circ}$ falls between $1.40^{\circ}$ (Experiment 1) and $1.42^{\circ}$ (Experiment 2). For the speed of $600 \mathrm{~mm} / \mathrm{min}$, the predicted value of $1.69^{\circ}$ falls between the corresponding experimental values of $1.67^{\circ}$ (Experiment 1 ) and $1.72^{\circ}$ (Experiment 2). A slight decrease in spring-in values from $1.15^{\circ}$ to $1.12^{\circ}$ can be observed with the reduction in pulling speed from 200 to $100 \mathrm{~mm} / \mathrm{min}$. Starting from $200 \mathrm{~mm} / \mathrm{min}$, the increase in pulling speed results in a considerable increase in spring-in values. Thus, the increase in pulling speed from 200 to $1000 \mathrm{~mm} / \mathrm{min}$ results in an over 3 times increase in spring-in (from $1.15^{\circ}$ to $3.60^{\circ}$ ). Figure 5 a also shows the fraction of uncured matrix material $(\alpha<85 \%)$ within the cross-section of the profile after the die exit. It can be seen that the increase in the fraction of uncured material at the die exit corresponds to an increase in the final values of spring-in. Thus, at the pulling speed of $200 \mathrm{~mm} / \mathrm{min}$, the exothermic peak is located inside the die block, and the composite exits the die block fully cured (see Figures $5 \mathrm{a}$ and $7 \mathrm{e}$ ), giving the final spring-in value of $1.15^{\circ}$. The increase in pulling speed forces the exothermic peak further along the pultrusion line, beyond the die block exit. Thus, at pulling speeds of $600 \mathrm{~mm} / \mathrm{min}$ and $1000 \mathrm{~mm} / \mathrm{min}$, the fraction of uncured resin within the cross-section of the profile constitutes 31\% (see Figures $5 \mathrm{a}$ and $7 \mathrm{f}$ ) and $81 \%$ (see Figures $5 \mathrm{a}$ and $7 \mathrm{~g}$ ), resulting in final spring-in values of $1.69^{\circ}$ and $3.60^{\circ}$, respectively. 


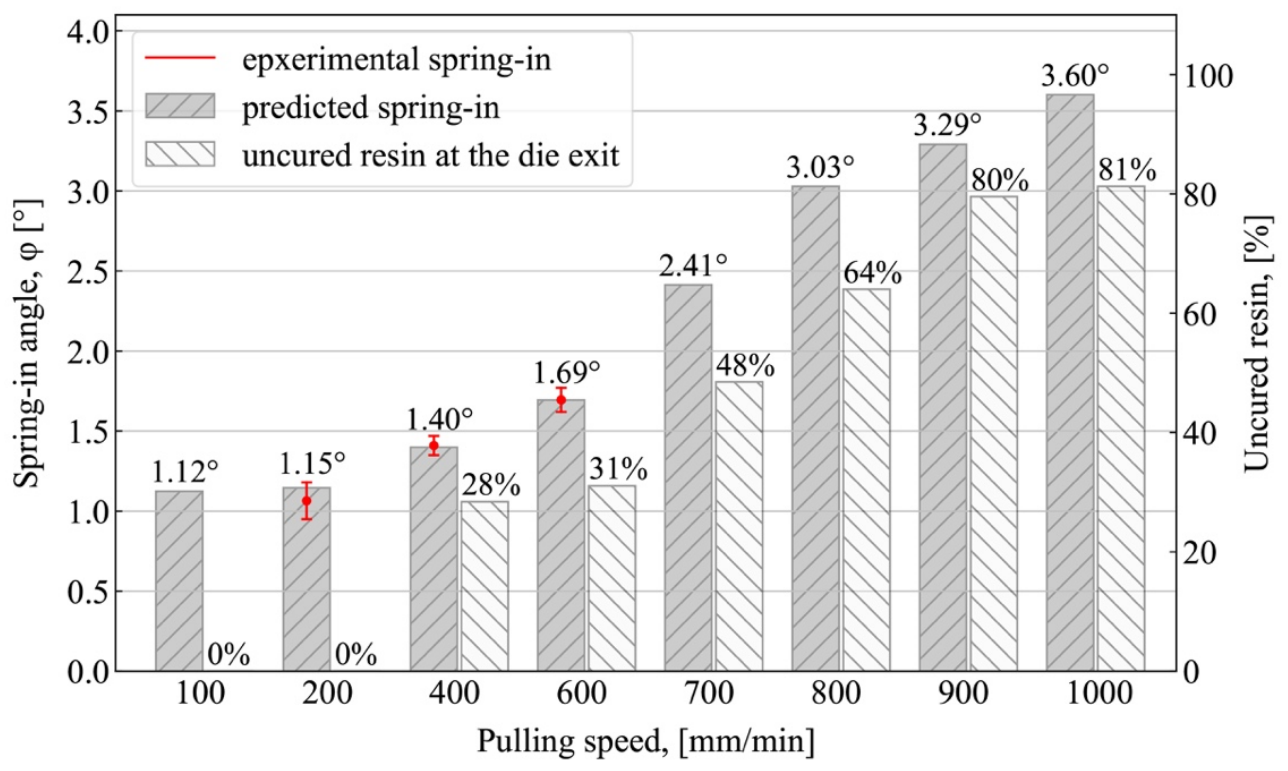

(a)



(b)

Figure 5. Numerical simulation results: (a) Final values of spring-in vs. fraction of uncured resin $(\alpha<85 \%)$ at the die exit for different pulling speeds, obtained with the model described in "Modeling"; (b) Spring-in evolution during fabrication for different pulling speeds, obtained with the model described in "Modeling". The solid lines in (b) correspond to Stage I (spring-in evolutions from the moment the profile exits the die block to the exothermic peak occurrence); the dot-dash line corresponds to Stage II (from the exothermic peak occurrence to the vitrification point); the dashed line corresponds to Stage III (after vitrification and to the full cooldown of the profile); the bold cross marks the occurrence of the exothermic peak; the bold point marks the vitrification point; the values shown in rectangles correspond to pulling speed ( $\mathrm{mm} / \mathrm{min}$ ). 


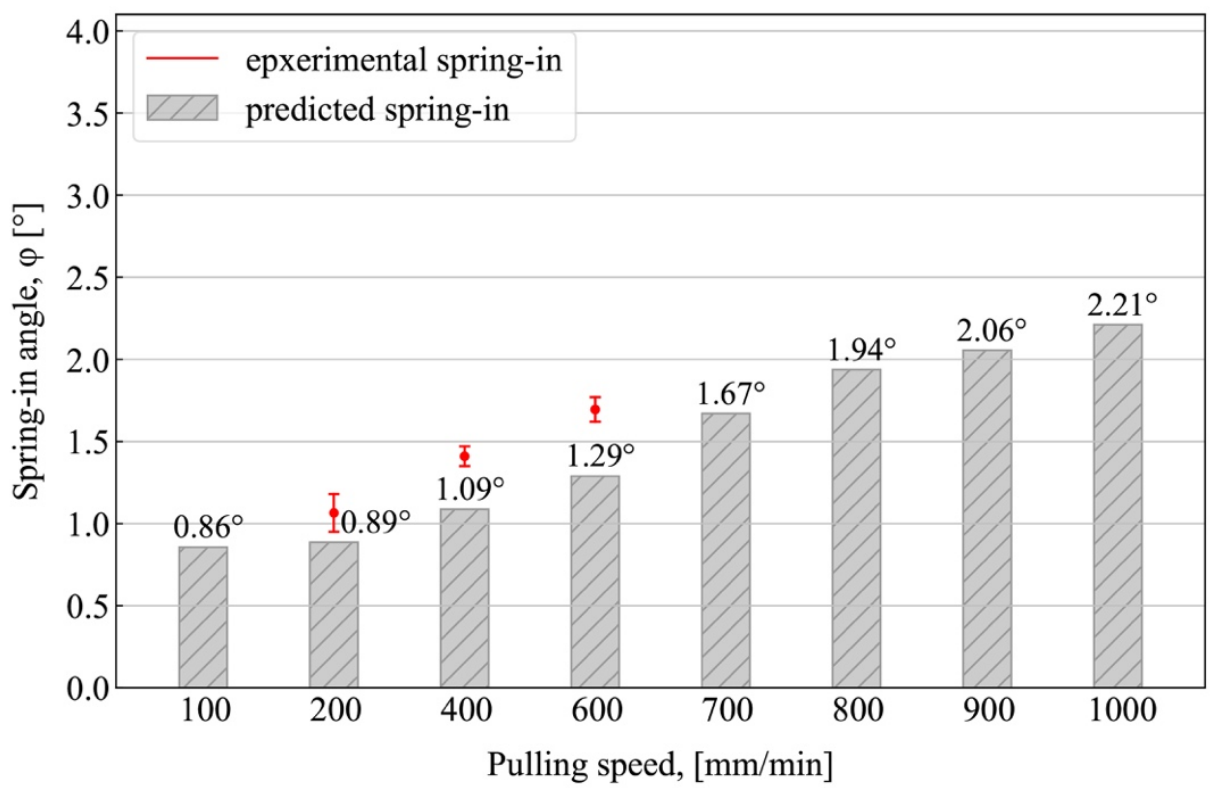

(a)



(b)

Figure 6. Numerical simulation results: (a) Final values of spring-in the die exit for different pulling speeds, assuming the constant Poisson's ratio of matrix; (b) Spring-in evolution during fabrication for different pulling speeds, assuming the constant Poisson's ratio of matrix. The solid lines in $(\mathbf{b})$ correspond to Stage I (spring-in evolutions from the moment the profile exits the die block and to the exothermic peak occurrence); the dot-dash line corresponds to Stage II (from the exothermic peak occurrence and to the vitrification point); the dashed line corresponds to Stage III (after vitrification and to the full cooldown of the profile); the bold cross marks the occurrence of the exothermic peak; the bold point marks the vitrification point; the values shown in rectangles correspond to pulling speed $(\mathrm{mm} / \mathrm{min})$. 


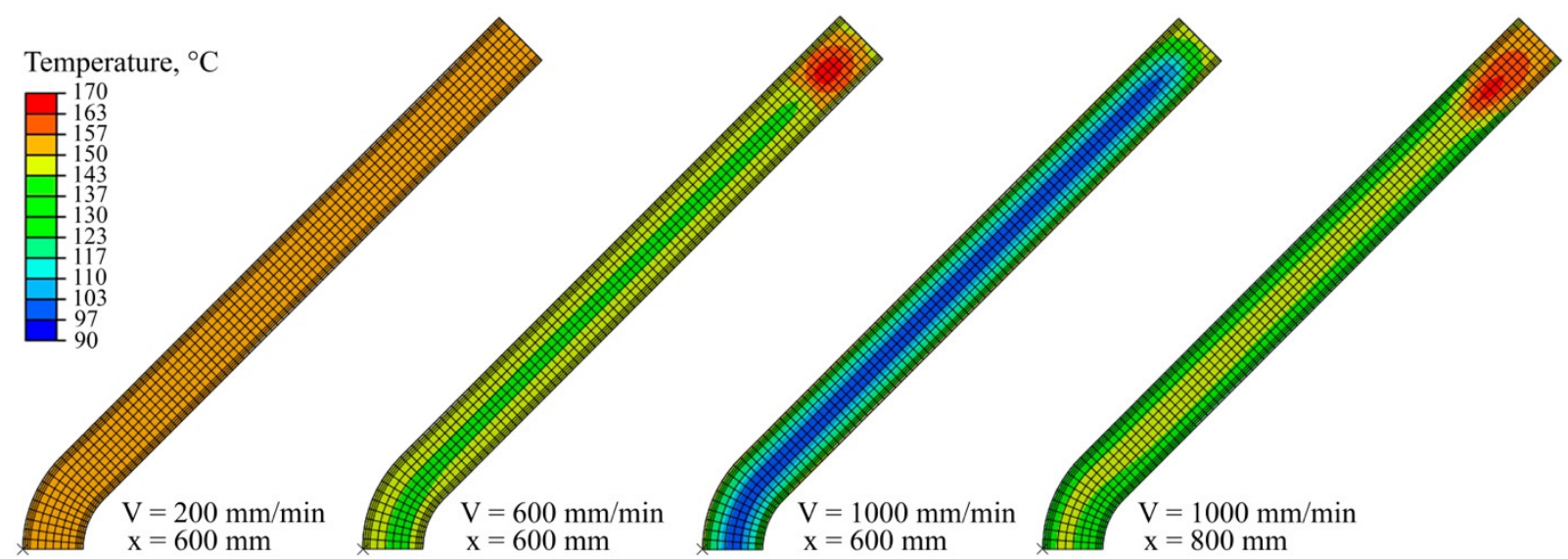

(a)

(b)

(c)

(d)



(e)

(f)

(h)

Figure 7. Simulation results: distribution of temperatures (a-d) and degree of polymerization (e-h) in the cross-section of the L-shaped profile: (a) pulling speed $-200 \mathrm{~mm} / \mathrm{min}$, immediately after the die exit; (b) pulling speed-600 $\mathrm{mm} / \mathrm{min}$, immediately after the die exit; (c) $1000 \mathrm{~mm} / \mathrm{min}$, immediately after the die exit; (d) $1000 \mathrm{~mm} / \mathrm{min}$, at $200 \mathrm{~mm}$ after the die exit, or immediately after the post-die cooling tool; (e) $200 \mathrm{~mm} / \mathrm{min}$, immediately after the die exit; (f) $600 \mathrm{~mm} / \mathrm{min}$, immediately after the die exit; (g) $1000 \mathrm{~mm} / \mathrm{min}$, immediately after the die exit; (h) $1000 \mathrm{~mm} / \mathrm{min}$, at $200 \mathrm{~mm}$ after the die exit or immediately after the post-die cooling tool. Exothermic peak and vitrification were analyzed in Zone E shown to the right in (h).

Table 1. Spring-in of L-shaped profiles pultruded at different pulling speeds (experimental results and predictions). Contributions of stages to the final spring-in value.

\begin{tabular}{|c|c|c|c|c|c|c|}
\hline \multirow[b]{3}{*}{$\begin{array}{l}\text { Pulling Speed } \\
{[\mathrm{mm} / \mathrm{min}]}\end{array}$} & \multicolumn{6}{|c|}{ Spring-In Angle $\left[{ }^{\circ}\right]$} \\
\hline & \multicolumn{2}{|c|}{ Experiment } & \multicolumn{4}{|c|}{ Model } \\
\hline & Experiment 1 & Experiment 2 & $\begin{array}{c}\text { Stage I } \\
\text { (From the Die Block } \\
\text { Exit to the } \\
\text { Exothermic Peak) }\end{array}$ & $\begin{array}{c}\text { Stage II } \\
\text { (From the Exothermic } \\
\text { Peak to the } \\
\text { Vitrification Point) }\end{array}$ & $\begin{array}{c}\text { STAGE III } \\
\text { (From Vitrification to } \\
\text { the Full Cooldown } \\
\text { of the Profile) }\end{array}$ & $\begin{array}{l}\text { Final } \\
\text { Value }\end{array}$ \\
\hline 100 & - & - & 0 & 0.97 & 0.15 & 1.12 \\
\hline 200 & 0.97 & 1.16 & 0 & 0.99 & 0.16 & 1.15 \\
\hline 400 & 1.40 & 1.42 & 0.45 & 0.80 & 0.15 & 1.40 \\
\hline 600 & 1.67 & 1.72 & 0.76 & 0.78 & 0.15 & 1.69 \\
\hline 700 & - & - & 1.46 & 0.80 & 0.15 & 2.41 \\
\hline 800 & - & - & 2.10 & 0.77 & 0.16 & 3.03 \\
\hline 900 & - & - & 2.38 & 0.75 & 0.16 & 3.29 \\
\hline 1000 & - & - & 2.72 & 0.72 & 0.16 & 3.60 \\
\hline
\end{tabular}


Figure $5 \mathrm{~b}$ shows the diagrams of spring-in changes during fabrication for pulling speeds of 200 to $1000 \mathrm{~mm} / \mathrm{min}$. The diagram shows three zones corresponding to three stages of spring-in evolution, as follows: Stage I (solid line) corresponds to spring-in changes from the moment the profile exits the die block and to the moment of exothermic peak occurrence (marked by the bold cross); Stage II (dotted and dashed line) corresponds to spring-in changes from the moment of the exothermic peak and to the vitrification point (marked by the bold point); Stage III (dashed line) corresponds to spring-in changes after vitrification and to the full cooldown of the profile. The occurrence of the exothermic peak and vitrification was analyzed within Zone E located at a distance of $2.23 \mathrm{~mm}$ from the internal surface of the profile along the $\mathrm{AD}$ axis of symmetry (Figure $7 \mathrm{~h}$ ), as simulations show that the maximum temperature of the exothermic peak over the whole section of a composite is observed exactly in this zone at all pulling speeds. Table 1 presents the final values of spring-in, together with the contributions of each stage described above.

Starting from the pulling speed of $400 \mathrm{~mm} / \mathrm{min}$, the largest contribution to the increase in final spring-in comes from the spring-in occurring at Stage I. This can be attributed to the increase in fraction of uncured material in a composite exiting the die block. It leads to an increase in the corresponding total chemical shrinkage of material in the unconstrained environment. Thus, Stage I $\left(2.72^{\circ}\right)$ contributes $76 \%$ to the final spring-in value obtained at $1000 \mathrm{~mm} / \mathrm{min}\left(3.60^{\circ}\right)$. This can be viewed as the quantitative confirmation of the qualitative results reported by Baran et al. in [48]. It should be noted that at low pulling speeds, the exothermic peak occurs within the die block and the contribution of Stage I to spring-in evolutions in the post-die region is virtually zero (see the corresponding values for pulling speeds of 100 and $200 \mathrm{~mm} / \mathrm{min}$ in Table 1). At Stage II, a slight decrease in spring-in can be observed with an increase in pulling speed, which is associated with the lower temperature of the exothermic peak. This phenomenon takes place when the exothermic peak occurs outside the die block. With an increase in pulling speed, the composite material stays in the die block for a shorter period of time and takes less heat from the die block. As the same material is considered, the amount of heat generated during the polymerization of the resin is constant and does not depend on the value of chosen pulling speed. Therefore, increasing the pulling speed, the amount of heat transmitted to the composite during pultrusion decreases, and, therefore, the temperature of the exothermic peak also decreases. The Stage III spring-in value virtually does not depend on the pulling speed and constitutes $0.15-0.16^{\circ}$. Thus, for a pulling speed of $1000 \mathrm{~mm} / \mathrm{min}$, contributions from Stages II and III to the final spring-in are $20 \%$ and $4 \%$, respectively.

Figure $6 \mathrm{a}, \mathrm{b}$ show the results of spring-in simulation for the pultruded L-shaped profile, assuming a constant Poisson's ratio of the matrix, $v_{\mathrm{r}}=0.35$. It can be seen that for a constant Poisson's ratio, the spring-in values are lower than those obtained in simulations that account for changes in Poisson's ratio in accordance with Equation (13). Thus, at the pulling speed of $100 \mathrm{~mm} / \mathrm{min}$, the spring-in obtained at a constant Poisson's ratio constitutes $0.86^{\circ}$, while when varying Poisson's ratio, the spring-in constitutes $1.12^{\circ}$, making the difference of $30 \%$. At the pulling speed of $1000 \mathrm{~mm} / \mathrm{min}$, the spring-in constitutes $2.21^{\circ}$ at a constant Poisson's ratio and $3.60^{\circ}$ at a varying Poisson's ratio, making the difference of $63 \%$. For simulations with a constant Poisson's ratio, predicted final values of spring-in are lower than those obtained in the second experiment conducted at pulling speeds of 200,400, and $600 \mathrm{~mm} / \mathrm{min}$ by up to $30 \%, 30 \%$, and $33 \%$, respectively.

Figure 8 shows the results of simulations conducted to estimate the efficiency of methods reducing the spring-in in composite parts, such as the use of a post-die cooling tool (Figure 8a), and the reduced chemical shrinkage of the matrix (Figure 8b). Figure 8a shows results of spring-in simulation in L-shaped profiles pultruded at different pulling speeds with the use of a rigid post-die cooling tool with a length constituting $1 / 3$ of that of the die block $\left(\mathrm{L}_{\text {die }} / 3\right)$, which was installed in a pultrusion manufacturing line immediately after the exit of the heated die block. 




(a)

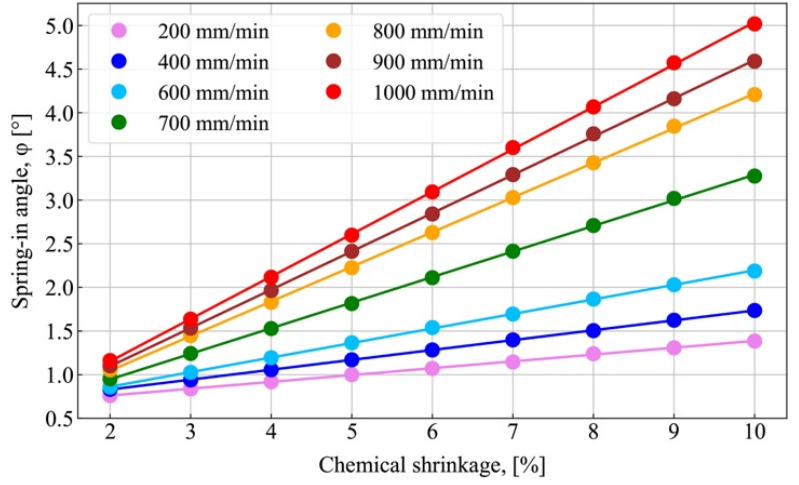

(b)

Figure 8. Simulation results for methods of spring-in reduction: (a) With the use of a post-die cooling tool. Gray columns mark the spring-in values obtained with the use of the post-die cooling tool; red lines indicate values obtained without the post-die cooling tool. The corresponding fraction of uncured resin $(\alpha<85 \%)$ is shown at the bottom of the graph; (b) Spring-in vs. chemical shrinkage of the resin at different pulling speeds (for shrinkage values within the range of 2 to $10 \%$ ).

To simulate the post-die cooling tool, boundary constraints within its region are set to prevent all motion at the outer perimeter of the profile (the ABCD segment in Figure 2c). The temperature conditions are set to simulate the cooling down of the profile after the die block exit according to Equation (4). After the exit from the post-die cooling tool, the boundary constraints are deactivated. As a result, a reduction in spring-in for all pulling speeds can be observed, as compared to the absence of the post-die cooling tool. The efficiency of the post-die cooling tool is more evident at higher pulling speeds. Thus, at low pulling speeds where the exothermic peak occurs within the die block, the reduction in spring-in constitutes $0.33^{\circ}$ and $0.26^{\circ}$ at $100 \mathrm{~mm} / \mathrm{min}$ and $200 \mathrm{~mm} / \mathrm{min}$, respectively. However, at pulling speeds of $400-900 \mathrm{~mm} / \mathrm{min}$, where the exothermic peak shifts to the region of a post-die cooling tool, a significant reduction in the final value of spring-in can be observed, which is associated with the absence of uncured material in the profile exiting the post-die cooling tool (Figure 8a). Thus, at a pulling speed of $900 \mathrm{~mm} / \mathrm{min}$, the use of the post-die cooling tool results in a final spring-in value of $1.05^{\circ}$, which is 3.1 times lower than the final value of spring-in $\left(3.29^{\circ}\right)$ obtained at the same pulling speed but without the post-die cooling tool. A slight reduction in the final spring-in from $1.17^{\circ}$ to $1.05^{\circ}$ within the pulling speed range of $400-900 \mathrm{~mm} / \mathrm{min}$ should also be noted, which can be attributed to the lower temperature of the exothermic peak; this affects the value of thermal shrinkage dependent on the temperature difference. With a further increase in pulling speed to $1000 \mathrm{~mm} / \mathrm{min}$, the exothermic peak shifts beyond the post-die cooling tool, resulting in the presence of uncured material at the exit of the post-die cooling tool and in chemical shrinkage taking place under unconstrained conditions. In turn, this results in the increased values of final spring-in compared to those obtained at pulling speeds of 400 to $900 \mathrm{~mm} / \mathrm{min}$. At the pulling speed of $1000 \mathrm{~mm} / \mathrm{min}$ and with the use of the post-die cooling tool, the final value of spring-in is $1.32^{\circ}$, which is 2.7 times lower than the value of $3.60^{\circ}$ obtained without the post-die cooling tool; this can be attributed to the lower fraction of uncured matrix material registered at the exit of the constrained environment of the post-die cooling tool, constituting $42 \%$ (see Figure 8 a) versus $81 \%$ registered at the exit of the die block (see Figure 5a). Therefore, the use of the post-die cooling tool can be considered an effective technique to prevent the increase in spring-in at higher pulling speeds by reducing the fraction of uncured material in a composite exiting the constrained environment and, consequently, reducing the total chemical shrinkage occurring in the unconstrained environment.

Figure $8 \mathrm{~b}$ shows the predictions of spring-in in L-shaped profiles pultruded at different pulling speeds for different values of chemical shrinkage in the range of 2 to $10 \%$. A linear relationship can be observed between the chemical shrinkage of the matrix and the value 
of spring-in. Chemical shrinkage has a greater influence on the value of spring-in at higher pulling speeds. Thus, the final values of spring-in obtained at $1000 \mathrm{~mm} / \mathrm{min}$ for $2 \%$ and $10 \%$ chemical shrinkage differ by a factor of 4.3 , as compared to 1.8 , which was obtained at a pulling speed of $200 \mathrm{~mm} / \mathrm{min}$. Therefore, the reduction of total chemical shrinkage is very important for resins with high chemical shrinkage as the difference between the final values of spring-in at different pulling speeds is particularly noticeable at higher values of chemical shrinkage.

\section{Discussion}

Spring-in formation in the post-die region takes place in three stages. Starting from the pulling speed of $400 \mathrm{~mm} / \mathrm{min}$, the largest contribution to the increase in final spring-in comes from Stage I located before the exothermic peak; this is associated with the exit of uncured resin from the die block and with the subsequent chemical shrinkage taking place in the unconstrained post-die region. The second contribution comes from Stage II, which takes place from the exothermic peak to the vitrification point. The lowest contribution to spring-in development comes from Stage III, which takes place from vitrification and to the complete cooldown of a composite. The increase in pulling speed raises the contribution from Stage I and reduces the role of Stage II, while the contribution from Stage III remains unchanged. Thus, for a pulling speed of $400 \mathrm{~mm} / \mathrm{min}$, the contributions to the final springin from Stages I, II, and III were $32 \%\left(0.45^{\circ}\right), 57 \%\left(0.8^{\circ}\right)$, and $11 \%\left(0.15^{\circ}\right)$, respectively. At $1000 \mathrm{~mm} / \mathrm{min}$, the corresponding contributions constitute $76 \%\left(2.72^{\circ}\right), 20 \%\left(0.72^{\circ}\right)$, and $4 \%$ $\left(0.16^{\circ}\right)$, respectively.

To increase the efficiency and, thus, the profit from the pultrusion process, it is necessary to maximize pulling speed while preserving the quality of pultruded profiles. Simulations show that lower pulling speeds result in a reduction in spring-in. However, after a certain limit (see Figure 5a), a reduction in pulling speed does not produce a meaningful reduction in spring-in. Thus, the difference between the spring-in values obtained at pulling speeds of 100 and $200 \mathrm{~mm} / \mathrm{min}$ was only $2.7 \%$. Therefore, a reduction in pulling speed below the value corresponding to the exothermic peak location at the boundary between the die block and the unconstrained post-die region will only result in reduced process output and will not affect spring-in. At lower pulling speeds, the chemical shrinkage providing the largest contribution to spring-in development occurs within the die block. Here, a composite is contained in constrained conditions and, consequently, experiences less deformation compared to the unconstrained environment of the post-die region. Conversely, higher pulling speeds shift the exothermic peak beyond the constrained region of the die block, resulting in higher spring-in values. Thus, final spring-in values obtained at $200 \mathrm{~mm} / \mathrm{min}$ (with an exothermic peak located inside the die block) and at $1000 \mathrm{~mm} / \mathrm{min}$ (with an exothermic peak located in the post die region), differ by the factor of 3.1 , constituting $1.15^{\circ}$ and $3.60^{\circ}$, respectively.

Hence, to increase the process output, the capability is needed to reduce the contributions from chemical and thermal shrinkages to trade the slight increase in spring-in for a significant increase in pulling speed. The spring-in can be reduced by installing a post-die cooling tool or by using additives that reduce chemical shrinkage of the resin (carbon nanofibers [41], silica nanoparticles [103], aluminum oxide nanoparticles [78], and low-profile additives [104]). The use of a post-die cooling tool makes it possible to significantly increase the process output by increasing the pulling speed without increasing the final spring-in value. Thus, using the post-die cooling tool at the pulling speed of $900 \mathrm{~mm} / \mathrm{min}$ makes it possible to obtain the same level of spring-in as at $200 \mathrm{~mm} / \mathrm{min}$ without the cooling tool. Thus, the pulling speed can be increased by a factor of 4.5 while maintaining the same level of spring-in, i.e., $1.05^{\circ}$ and $1.15^{\circ}$, respectively (see Figure 8a). The efficiency of this method can be explained by the smaller fraction of uncured material exiting the constrained environment. In turn, this results in a reduction in the total chemical shrinkage of a profile under unconstrained conditions. Thus, at $900 \mathrm{~mm} / \mathrm{min}$, the final value of spring-in obtained with the use of the post-die cooling tool is $1.05^{\circ}$, which is 
3.1 times less than that obtained without the use of a cooling tool, where the final spring-in constitutes $3.29^{\circ}$.

Reduction of the total chemical shrinkage is also a very effective method of reducing the spring-in, which plays an important role in the case of resins featuring high chemical shrinkage because the difference between the final values of spring-in at different pulling speeds becomes more evident at higher values of chemical shrinkage. Thus, for resins with chemical shrinkage of $10 \%$, the final values of spring-in obtained at pulling speeds of $200 \mathrm{~mm} / \mathrm{min}$ and $1000 \mathrm{~mm} / \mathrm{min}$ differ by a factor of 3.6, i.e., $1.39^{\circ}$ and $5.02^{\circ}$, respectively. For resins with $2 \%$ chemical shrinkage, the corresponding values differ only by a factor of 1.5 , i.e., $0.76^{\circ}$ and $1.16^{\circ}$, respectively. In addition, at a pulling speed of $1000 \mathrm{~mm} / \mathrm{min}$, the use of additives to reduce the chemical shrinkage of resin from 7 to $2 \%$ makes it possible to obtain the level of spring-in equal to that of a resin with a chemical shrinkage of $7 \%$ without additives, at a pulling speed of $200 \mathrm{~mm} / \mathrm{min}$. That is, the pulling speed can be increased by as much as five times, maintaining constant spring-in values of $1.16^{\circ}$ and $1.15^{\circ}$, respectively (see Figure $8 b$ ). The methods of reducing spring-in via the post-die cooling tool or with shrinkage-reducing additives require further investigation and experimental validation.

This 2D model is limited in that it does not account for changes in heat conduction in the pulling direction. However, it uses boundary conditions to account for the influence of pulling speed. The assumptions used in the model can lead to an overestimated exothermic peak as compared to the experimental values. In addition, the model does not account for stresses along the profile that can lead to additional shape deformations in the longitudinal direction. Nevertheless, these assumptions can be considered allowable in stress-strain analysis, considering large dimensions of produced profile in the pulling direction. In addition, these assumptions produce acceptable predictions of spring-in falling within spring-in values obtained in two pultrusion experiments. In future research, the authors intend to perform 3D analysis for the case of pultruded flat laminate to evaluate the influence of pulling speed and of profile thickness on the formation of cracks and distortions. Thus, a novel steady-state 3D-Eulerian numerical framework is intended to be applied in future works with the aim of accelerating the computational process [31].

The results of this study support findings in Baran et al. [48] that higher pulling speeds lead to increase in spring-in. However, their study is somewhat limited in that it analyzed only four different pulling speeds, and simulation results were experimentally validated only at one pulling speed. Consequently, the authors were unable to conclude that the decrease in spring-in observed with a reduction of pulling speed takes place only to a certain level, and that further reduction of pulling speed would not change the spring-in level. In their simulations, Baran et al. $[48,49]$ assumed the constant and temperatureindependent heat capacity of a composite. Considering that, according to our studies, heat capacity significantly affects the final value of spring-in, the assumption of constant and temperature-independent heat capacity of a composite appears unreasonable and will result in considerable disagreement between experimental results and predictions. Our study also demonstrate that chemical shrinkage plays a significant role in spring-in development in pultruded profiles, supporting the results reported by Wang et al. [70]. Moreover, the results obtained by Wang et al. are further extended in our study by calculating the contribution of thermal and chemical shrinkage to the growth of springin. The simulations demonstrated that reduced chemical shrinkage results in spring-in reduction, as shown in experiments with additives [41,78]. Moreover, the additives can also reduce the coefficient of thermal expansion of resin and, therefore, the spring-in angle, as shown in [81]. However, no experimental studies on the influence of additives on the development of cure-induced residual stresses and deformations in pultruded profiles have been published before. Therefore, this question will require further investigation. A significant reduction of cure-induced strains and spring-in can also be achieved through the use of microwave curing, as was demonstrated by Li et al. [47]. The influence of microwave processing on cure-induced strains in pultrusion also requires further investigation, as the application of this process seems to be quite possible [105]. Further experimental 
investigation of chemical shrinkage in pultrusion is intended to be performed with the use of Fiber Bragg Grating sensors as was done for autoclave technology by Hu et al. [77]. In addition, at high pulling speeds, it is necessary to consider the possible formation of matrix cracks and delamination, reducing the structural performance of pultruded profiles [60]. Therefore, further numerical studies are necessary to analyze the influence of the pultrusion process conditions on the formation of matrix cracks and delamination. It is also necessary to conduct multicriteria optimization of manufacturing conditions to maximize the pulling speed and minimize cure-induced residual stresses, spring-in, and formation of matrix cracks/delaminations, as was already done for other processes $[73,106]$. The effect of fiber volume fraction variability on the development of residual stresses and, therefore, on spring-in occurrence is to be investigated as well [30]. The authors also intend to simulate the formation of process-induced defects (spring-in, matrix cracks, delaminations) and their influence on the structural performance of other standard [107-109], curved [20], and new types of profiles designed using topology optimization methods [110].

\section{Conclusions}

To better understand the formation of spring-in in profiles manufactured at different pulling speeds, an experimental study and numerical simulation of $75 \mathrm{~mm} \times 75 \mathrm{~mm} \times$ $6 \mathrm{~mm}$ L-shaped profiles of glass fiber/vinyl ester resin has been conducted. The modified CHILE model accounting for changes in theYoung's modulus and Poisson's ratio during phase transitions was used for simulations. The occurrence of spring-in in L-shaped profiles manufactured at pulling speeds of 200, 400 , and $600 \mathrm{~mm} / \mathrm{min}$ was simulated. Then, the simulation results were compared with experimental values obtained in two pultrusion experiments conducted at the interval of 6 months. The predictions show good agreement with the experimental data. The validated model was also used to simulate the influence of pulling speed and of changes in the Poisson's ratio of the matrix during phase transitions on the value of spring-in. Subsequently, the methods of reducing spring-in with the use of a post-die cooling tool and by reducing the chemical shrinkage of the resin were simulated. The following findings can be reported:

- The final value of spring-in depends on the position of the exothermic peak and vitrification point on the pultrusion line, relative to the end of the constrained region of the die, which, in turn, is determined by the selected pulling speed. The closer the exothermic peak position to the constrained region of the die, the lower the obtained spring-in values. Alternatively, higher spring-in values can be observed with the increase in the distance of the peak from the die exit because the composite can no longer sustain stresses from chemical shrinkage in the unconstrained environment of the post-die region. It was shown that higher pulling speeds result in a higher fraction of uncured material in a composite exiting the constrained environment of the die block. This leads to an increase in the total chemical shrinkage of the material under unconstrained conditions and, hence, results in increased values of spring-in;

- Starting from the pulling speed of $400 \mathrm{~mm} / \mathrm{min}$, the largest contribution to springin comes from the chemical shrinkage of the resin, which takes place before the exothermic peak (Stage I), and from thermal shrinkage taking place before vitrification of the composite (Stage II). However, at the cooling stage (Stage III), thermal shrinkage resulted only in a slight increase in spring-in. The higher pulling speeds increase the contribution from Stage I and reduce the role of Stage II, while the spring-in contribution from Stage III remains unchanged;

- The use of a post-die cooling tool or reduction of resin chemical shrinkage allows a minimum of 4.5 times increase in process output to be obtained while preserving the same level of spring-in.

Supplementary Materials: The following are available online at https://www.mdpi.com/article/10 $.3390 /$ polym13162748/s1, Supplementary materials: Calculation of composite properties for heattransfer problem and composite effective mechanical properties. 
Author Contributions: Conceptualization, A.S.; software, A.V. and A.S.; validation, A.V. and A.S.; formal analysis, A.V. and A.S.; investigation, A.V.; data curation, A.V., A.S. and F.T.; writing-original draft preparation, A.V. and A.S.; writing-review and editing, A.V., A.S., F.T. and P.C.; visualization, A.V.; supervision, A.S. and P.C.; project administration, I.A.; funding acquisition, I.A. All authors have read and agreed to the published version of the manuscript.

Funding: This research received no external funding.

Data Availability Statement: The data presented in this study are available on request from the corresponding author.

Acknowledgments: The authors would like to express their gratitude to the Skoltech Center for Design, Manufacturing and Materials for the support provided within the framework of the collaboration programs.

Conflicts of Interest: The authors declare no conflict of interest.

\section{Notations}

\begin{tabular}{|c|c|}
\hline$\rho_{\mathrm{r}}$ & density of resin, $\mathrm{kg} / \mathrm{m}^{3}$ \\
\hline$\rho_{\mathrm{f}}$ & density of fiber, $\mathrm{kg} / \mathrm{m}^{3}$ \\
\hline$\rho_{\text {comp }}$ & density of composite, $\mathrm{kg} / \mathrm{m}^{3}$ \\
\hline $\mathrm{k}_{\mathrm{r}}$ & thermal conductivity of resin, $\mathrm{W} /\left(\mathrm{m} \cdot{ }^{\circ} \mathrm{C}\right)$ \\
\hline $\mathrm{k}_{\mathrm{f} \_ \text {trans }}$ & thermal conductivity of the fiber in the transverse direction, $\mathrm{W} /\left(\mathrm{m} \cdot{ }^{\circ} \mathrm{C}\right)$ \\
\hline $\mathrm{k}_{\mathrm{f} \_l o n g}$ & thermal conductivity of the fiber in the longitudinal direction, $\mathrm{W} /\left(\mathrm{m} \cdot{ }^{\circ} \mathrm{C}\right)$ \\
\hline $\mathrm{k}_{\text {comp }}$ & thermal conductivity in the cross-sectional plane, $\mathrm{W} /\left(\mathrm{m} \cdot{ }^{\circ} \mathrm{C}\right)$ \\
\hline $\mathrm{T}$ & instantaneous temperature, ${ }^{\circ} \mathrm{C}$ \\
\hline $\mathrm{C}_{\mathrm{p} \_\mathrm{r}}(\mathrm{T})$ & temperature-dependent heat capacity of resin, $\mathrm{J} /\left(\mathrm{kg} \cdot{ }^{\circ} \mathrm{C}\right)$ \\
\hline $\mathrm{C}_{\mathrm{p} \_\mathrm{f}}$ & heat capacity of the fiber, $\mathrm{J} /\left(\mathrm{kg} \cdot{ }^{\circ} \mathrm{C}\right)$ \\
\hline $\mathrm{C}_{\mathrm{p} \_ \text {comp }}(\mathrm{T})$ & temperature-dependent heat capacity of a composite, $\mathrm{J} /\left(\mathrm{kg} \cdot{ }^{\circ} \mathrm{C}\right)$ \\
\hline $\mathrm{t}$ & time, sec \\
\hline q & heat released due to the exothermic reaction in polymer matrix, $\mathrm{kJ}$ \\
\hline $\mathrm{x}, \mathrm{y}$ & coordinates of a cross-section of the composite profile, $\mathrm{mm}$ \\
\hline Z & $\begin{array}{l}\text { coordinate of a composite cross-section along the pulling direction of } \\
\text { pultrusion, } \mathrm{mm}\end{array}$ \\
\hline $\mathrm{h}_{\text {die }}$ & $\begin{array}{l}\text { convective heat transfer coefficient between the die block and the profile, } \\
\mathrm{W} /\left(\mathrm{m}^{2} \cdot{ }^{\circ} \mathrm{C}\right)\end{array}$ \\
\hline $\mathrm{h}_{\text {air }}$ & $\begin{array}{l}\text { convective heat transfer coefficient between the ambient air and the profile } \\
\text { after the die block exit, } \mathrm{W} /\left(\mathrm{m}^{2} \cdot{ }^{\circ} \mathrm{C}\right)\end{array}$ \\
\hline$\alpha$ & resin degree of cure \\
\hline $\mathrm{d} \alpha / \mathrm{dt}$ & resin curing rate, $1 / \mathrm{s}$ \\
\hline $\mathrm{A}_{0}$ & pre-exponential coefficient, $1 / \mathrm{s}$ \\
\hline $\mathrm{E}_{\mathrm{a}}$ & activation energy, $\mathrm{kJ} / \mathrm{mol}$ \\
\hline $\mathrm{R}$ & universal gas constant, $\mathrm{J} /\left(\mathrm{mol} \cdot{ }^{\circ} \mathrm{C}\right)$ \\
\hline $\mathrm{n}$ & order of reaction \\
\hline $\mathrm{K}_{\text {cat }}$ & activation constant \\
\hline $\mathrm{H}_{\text {tot }}$ & total heat released, $\mathrm{kJ} / \mathrm{kg}$ \\
\hline $\mathrm{T}_{\text {in }}$ & temperature of material at the die block entrance, ${ }^{\circ} \mathrm{C}$ \\
\hline $\mathrm{T}_{\text {die }}$ & temperature at the die block, ${ }^{\circ} \mathrm{C}$ \\
\hline $\mathrm{T}_{1}$ & temperature at the first zone of the die block, ${ }^{\circ} \mathrm{C}$ \\
\hline $\mathrm{T}_{2}$ & temperature at the second zone of the die block, ${ }^{\circ} \mathrm{C}$ \\
\hline $\mathrm{T}_{3}$ & temperature at the third zone of the die block, ${ }^{\circ} \mathrm{C}$ \\
\hline $\mathrm{T}_{4}$ & temperature at the fourth zone of the die block, ${ }^{\circ} \mathrm{C}$ \\
\hline $\mathrm{T}_{5}$ & temperature at the fifth zone of the die block, ${ }^{\circ} \mathrm{C}$ \\
\hline $\mathrm{T}_{6}$ & temperature at the die block exit, ${ }^{\circ} \mathrm{C}$ \\
\hline $\mathrm{T}_{\mathrm{amb}}$ & ambient temperature, ${ }^{\circ} \mathrm{C}$ \\
\hline $\mathrm{T}_{\mathrm{g}}(\alpha)$ & instantaneous glass transition temperature, ${ }^{\circ} \mathrm{C}$ \\
\hline $\mathrm{T}_{\mathrm{g} 0}$ & glass transition temperature of uncured resin, ${ }^{\circ} \mathrm{C}$ \\
\hline $\mathrm{T}_{\mathrm{g} \infty}$ & glass transition temperature of fully cured resin, ${ }^{\circ} \mathrm{C}$ \\
\hline $\mathrm{T}^{*}$ & $\begin{array}{l}\text { difference between the instantaneous glass transition temperature and the } \\
\text { instantaneous temperature of the resin, }{ }^{\circ} \mathrm{C}\end{array}$ \\
\hline $\mathrm{T}_{\mathrm{c} 1}, \mathrm{~T}_{\mathrm{c} 2}, \mathrm{~T}_{\mathrm{c} 3}, \mathrm{~T}_{\mathrm{c} 4}, \mathrm{~T}_{\mathrm{c} 5}, \mathrm{~T}_{\mathrm{c} 6}$ & critical temperatures, ${ }^{\circ} \mathrm{C}$ \\
\hline $\mathrm{E}_{\mathrm{r}}$ & instantaneous Young's modulus of the resin, $\mathrm{MPa}$ \\
\hline $\mathrm{E}_{\mathrm{r}}^{0}$ & Young's modulus of resin at $\mathrm{T}_{\mathrm{c} 1}=-30.8^{\circ} \mathrm{C}, \mathrm{MPa}$ \\
\hline $\mathrm{E}_{\mathrm{r}}^{1}$ & Young's modulus of resin at $\mathrm{T}_{\mathrm{c} 2}=0.7^{\circ} \mathrm{C}, \mathrm{MPa}$ \\
\hline $\mathrm{E}_{\mathrm{r}}^{2}$ & Young's modulus of resin at $\mathrm{T}_{\mathrm{c} 3}=18.4^{\circ} \mathrm{C}, \mathrm{MPa}$ \\
\hline
\end{tabular}




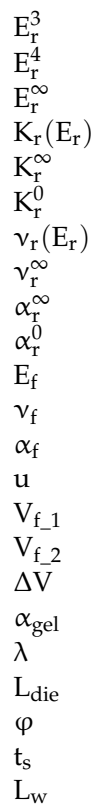

\section{Appendix A}

\author{
Young's modulus of resin at $\mathrm{T}_{\mathrm{c} 4}=30.5^{\circ} \mathrm{C}, \mathrm{MPa}$ \\ Young's modulus of resin at $\mathrm{T}_{\mathrm{c} 5}=62.6^{\circ} \mathrm{C}, \mathrm{MPa}$ \\ Young's modulus of resin at $\mathrm{T}_{\mathrm{c} 6}=95.1^{\circ} \mathrm{C}, \mathrm{MPa}$ \\ instantaneous bulk modulus of resin, $\mathrm{MPa}$ \\ bulk modulus of resin at $\mathrm{T}=25.3^{\circ} \mathrm{C}, \mathrm{MPa}$ \\ bulk modulus of resin at $\mathrm{T}=\mathrm{T}_{\mathrm{g} \infty}, \mathrm{MPa}$ \\ instantaneous Poisson's ratio of resin \\ Poisson's ratio of resin at $\mathrm{T}=25.3^{\circ} \mathrm{C}$ \\ coefficient of thermal expansion of resin at $\mathrm{T}<\mathrm{T}_{\mathrm{g} \infty}, 1 /{ }^{\circ} \mathrm{C}$ \\ coefficient of thermal expansion of resin at $\mathrm{T} \geq \mathrm{T}_{\mathrm{g} \infty}, 1 /{ }^{\circ} \mathrm{C}$ \\ Young's modulus of glass fiber reinforcement, $\mathrm{MPa}$ \\ Poisson's ratio of glass fiber reinforcement \\ coefficient of thermal expansion of glass fiber reinforcement, $1 /{ }^{\circ} \mathrm{C}$ \\ pulling speed, $\mathrm{mm} / \mathrm{min}$ \\ volume fraction of fabric layer reinforcement \\ volume fraction of unidirectional layer reinforcement \\ total volumetric chemical shrinkage, $\%$ \\ resin cure degree corresponding to the gelation \\ material constant in Equation (10) \\ die block length, $\mathrm{m}$ \\ spring-in angle, ${ }^{\circ}$ \\ thickness of the strips, $\mathrm{mm}$ \\ size of the L-shaped profile legs, $\mathrm{mm}$
}

Table A1. Model parameters.

\begin{tabular}{|c|c|c|c|c|c|c|}
\hline Property & Source & Symbol & \multicolumn{3}{|c|}{ Value } & Unit \\
\hline \multicolumn{7}{|c|}{ Heat transfer problem } \\
\hline Density of resin & $-\mathrm{a}$ & $\rho_{\mathrm{r}}$ & & 1140 & & $\mathrm{~kg} / \mathrm{m}^{3}$ \\
\hline Density of fiber & [49] & $\rho_{\mathrm{f}}$ & & 2560 & & $\mathrm{~kg} / \mathrm{m}^{3}$ \\
\hline Thermal conductivity of resin & $-\mathrm{e}$ & $\mathrm{k}_{\mathrm{r}}$ & & 0.178 & & $\mathrm{~W} /\left(\mathrm{m} \cdot{ }^{\circ} \mathrm{C}\right)$ \\
\hline $\begin{array}{c}\text { Thermal conductivity of fiber in the transverse } \\
\text { direction }\end{array}$ & [49] & $\mathrm{k}_{\mathrm{f} \_ \text {trans }}$ & & 1.04 & & $\mathrm{~W} /\left(\mathrm{m} \cdot{ }^{\circ} \mathrm{C}\right)$ \\
\hline $\begin{array}{l}\text { Thermal conductivity of fiber in the longitudinal } \\
\text { direction }\end{array}$ & [49] & $\mathrm{k}_{\mathrm{f} \_l o n g}$ & & 11.4 & & $\mathrm{~W} /\left(\mathrm{m} \cdot{ }^{\circ} \mathrm{C}\right)$ \\
\hline $\begin{array}{l}\text { Heat capacity of resin depending on the } \\
\text { temperature }\end{array}$ & $-b$ & $\mathrm{C}_{\mathrm{p} \_\mathrm{r}}(\mathrm{T})$ & & $5.1 \times \mathrm{T}+1$ & & $\mathrm{~J} /\left(\mathrm{kg} \cdot{ }^{\circ} \mathrm{C}\right)$ \\
\hline Heat capacity of fiber & [49] & $\mathrm{C}_{\mathrm{p} \__{-} \mathrm{f}}$ & & 670 & & $\mathrm{~J} /\left(\mathrm{kg} \cdot{ }^{\circ} \mathrm{C}\right)$ \\
\hline $\begin{array}{l}\text { Convective heat transfer coefficient between the } \\
\text { die block and the profile }\end{array}$ & $-f$ & $\mathrm{~h}_{\mathrm{die}}$ & & 5000 & & $\mathrm{~W} /\left(\mathrm{m}^{2} \cdot{ }^{\circ} \mathrm{C}\right)$ \\
\hline $\begin{array}{l}\text { Convective heat transfer coefficient between the } \\
\text { ambient air and the profile after the die block exit }\end{array}$ & $-f$ & $\mathrm{~h}_{\text {air }}$ & & 9 & & $\mathrm{~W} /\left(\mathrm{m}^{2} \cdot{ }^{\circ} \mathrm{C}\right)$ \\
\hline \multicolumn{7}{|c|}{ Cure kinetics } \\
\hline Pre-exponential coefficient & [90] & $\mathrm{A}_{0}$ & & $10^{9.34}$ & & $1 / \mathrm{s}$ \\
\hline Activation energy & [90] & $\mathrm{E}_{\mathrm{a}}$ & & 93.3 & & $\mathrm{~kJ} / \mathrm{mol}$ \\
\hline Universal gas constant & [90] & $\mathrm{R}$ & & 8.31 & & $\mathrm{~J} /\left(\mathrm{mol} \cdot{ }^{\circ} \mathrm{C}\right)$ \\
\hline Order of reaction & [90] & $\mathrm{n}$ & & 1.91 & & - \\
\hline Activation constant & [90] & $\mathrm{K}_{\text {cat }}$ & & $10^{2.73}$ & & - \\
\hline Total heat released & [90] & $\mathrm{H}_{\text {tot }}$ & & 189 & & $\mathrm{~kJ} / \mathrm{kg}$ \\
\hline \multicolumn{7}{|c|}{ Temperature conditions } \\
\hline \multirow{2}{*}{\multicolumn{2}{|c|}{ Temperature at the die block, $\mathrm{T}_{\text {die }}(\mathrm{z})$ : }} & \multicolumn{5}{|c|}{ Pulling speed, $\mathrm{mm} / \mathrm{min}$} \\
\hline & & & 200 & 400 & 600 & \\
\hline @ 97-103 mm (1st zone) & $-\mathrm{a}$ & $\mathrm{T}_{1}$ & 45 & 31 & 30 & ${ }^{\circ} \mathrm{C}$ \\
\hline @ 197-203 mm (2nd zone) & $-\mathrm{a}$ & $\mathrm{T}_{2}$ & 62 & 42 & 40 & ${ }^{\circ} \mathrm{C}$ \\
\hline @ 297-303 mm (3rd zone) & $-\mathrm{a}$ & $\mathrm{T}_{3}$ & 84 & 66 & 89 & ${ }^{\circ} \mathrm{C}$ \\
\hline @ 397-403 mm (4th zone) & $-\mathrm{a}$ & $\mathrm{T}_{4}$ & 127 & 95 & 119 & ${ }^{\circ} \mathrm{C}$ \\
\hline @ 497-503 mm (5th zone) & $-\mathrm{a}$ & $\mathrm{T}_{5}$ & 159 & 127 & 141 & ${ }^{\circ} \mathrm{C}$ \\
\hline @ $600 \mathrm{~mm}$ (at the die block exit) & $-\mathrm{a}$ & $\mathrm{T}_{6}$ & 153 & 148 & 147 & ${ }^{\circ} \mathrm{C}$ \\
\hline Temperature of material at the die block entrance & $-\mathrm{a}$ & $\mathrm{T}_{\mathrm{in}}$ & & 18 & & ${ }^{\circ} \mathrm{C}$ \\
\hline Ambient temperature & $-\mathrm{a}$ & $\mathrm{T}_{\mathrm{amb}}$ & & 18 & & ${ }^{\circ} \mathrm{C}$ \\
\hline
\end{tabular}


Table A1. Cont.

\begin{tabular}{|c|c|c|c|c|}
\hline Property & Source & Symbol & Value & Unit \\
\hline \multicolumn{5}{|c|}{ Mechanical properties of resin } \\
\hline Young's modulus at $\mathrm{T}_{\mathrm{c} 1}=-30.8^{\circ} \mathrm{C}$ & $-\mathrm{c}$ & $\mathrm{E}_{\mathrm{r}}^{0}$ & 21 & $\mathrm{MPa}$ \\
\hline Young's modulus at $\mathrm{T}_{\mathrm{c} 2}=0.7^{\circ} \mathrm{C}$ & $-\mathrm{c}$ & $\mathrm{E}_{\mathrm{r}}^{1}$ & 86 & $\mathrm{MPa}$ \\
\hline Young's modulus at $\mathrm{T}_{\mathrm{c} 3}=18.4^{\circ} \mathrm{C}$ & $-c$ & $E_{r}^{2}$ & 1961 & $\mathrm{MPa}$ \\
\hline Young's modulus at $\mathrm{T}_{\mathrm{c} 4}=30.5^{\circ} \mathrm{C}$ & $-\mathrm{c}$ & $E_{r}^{3}$ & 2473 & $\mathrm{MPa}$ \\
\hline Young's modulus at $\mathrm{T}_{\mathrm{c} 5}=62.6^{\circ} \mathrm{C}$ & $-c$ & $\mathrm{E}_{\mathrm{r}}^{4}$ & 3083 & $\mathrm{MPa}$ \\
\hline Young's modulus at $\mathrm{T}_{\mathrm{c} 6}=95.1^{\circ} \mathrm{C}$ & $-\mathrm{c}$ & $\mathrm{E}_{\mathrm{r}}^{\infty}$ & 3421 & $\mathrm{MPa}$ \\
\hline Poisson's ratio at $\mathrm{T}=25.3^{\circ} \mathrm{C}$ & [111] & $v_{\mathrm{r}}^{\infty}$ & 0.35 & - \\
\hline Bulk modulus at $\mathrm{T}=25.3^{\circ} \mathrm{C}$ & $\frac{E_{\mathrm{r}}^{\infty}}{3\left(1-2 v_{\mathrm{r}}^{\infty}\right)}$ & $\mathrm{K}_{\mathrm{r}}^{\infty}$ & 3801 & $\mathrm{MPa}$ \\
\hline Bulk modulus at $\mathrm{T}=\mathrm{T}_{\mathrm{g} \infty}$ & $\frac{\mathrm{K}_{\mathrm{r}}^{\infty}}{2.5}[56]$ & $\mathrm{K}_{\mathrm{r}}^{0}$ & 1520 & $\mathrm{MPa}$ \\
\hline Coefficient of thermal expansion at $\mathrm{T}<\mathrm{T}_{\mathrm{g} \infty}$ & ${ }^{2.5}-\mathrm{d}$ & $\alpha_{\mathrm{r}}^{\infty}$ & $60 \times 10^{-6}$ & $1 /{ }^{\circ} \mathrm{C}$ \\
\hline Coefficient of thermal expansion at $\mathrm{T} \geq \mathrm{T}_{\mathrm{g} \infty}$ & $2.5 \times \alpha_{\mathrm{r}}^{\infty}[56]$ & $\alpha_{\mathrm{r}}^{0}$ & $150 \times 10^{-6}$ & $1 /{ }^{\circ} \mathrm{C}$ \\
\hline \multicolumn{5}{|c|}{ Mechanical properties of glass fiber reinforcement } \\
\hline Young's modulus & [57] & $E_{f}$ & 73080 & $\mathrm{MPa}$ \\
\hline Poisson's ratio & [57] & $v_{\mathrm{f}}$ & 0.22 & - \\
\hline Coefficient of thermal expansion & [57] & $\alpha_{\mathrm{f}}$ & $5.04 \times 10^{-6}$ & $1 /{ }^{\circ} \mathrm{C}$ \\
\hline \multicolumn{5}{|c|}{ Other properties } \\
\hline Pulling speed & $-\mathrm{a}$ & $\mathrm{u}$ & $200 / 400 / 600$ & $\mathrm{~mm} / \mathrm{min}$ \\
\hline \multicolumn{5}{|l|}{ The volume fraction of reinforcement } \\
\hline Fabric layer & $-\mathrm{a}$ & $\mathrm{V}_{\mathrm{f} \_1}$ & 0.5 & - \\
\hline UD layer & $-\mathrm{a}$ & $V_{f \_2}$ & 0.59 & - \\
\hline Total volumetric chemical shrinkage & [100] & $\Delta \mathrm{V}$ & -7 & $\%$ \\
\hline Glass transition temperature of the uncured resin & [56] & $\mathrm{T}_{\mathrm{g} 0}$ & -41 & ${ }^{\circ} \mathrm{C}$ \\
\hline $\begin{array}{l}\text { Glass transition temperature of the fully cured } \\
\text { resin }\end{array}$ & $-c$ & $\mathrm{~T}_{\mathrm{g} \infty}$ & 120.4 & ${ }^{\circ} \mathrm{C}$ \\
\hline Resin cure degree corresponding to the gelation & $-f$ & $\alpha_{\text {gel }}$ & 0.6 & - \\
\hline Material constant in Equation (10) & [49] & $\lambda$ & 0.4 & - \\
\hline Die block length & $-a$ & $\mathrm{~L}_{\text {die }}$ & 0.6 & $\mathrm{~m}$ \\
\hline
\end{tabular}

${ }^{a}$ Measured value in pultrusion experiments. ${ }^{b}$ Determined from Differential Scanning Calorimetry (DSC) data. ${ }^{c}$ Determined from Dynamic Mechanical Analysis (DMA) data. ${ }^{\mathrm{d}}$ Determined from Thermomechanical Analysis (TMA) data. ${ }^{\mathrm{e}}$ Determined from Laser Flash Analysis (LFA) data. ${ }^{\mathrm{f}}$ Assumed value.

\section{References}

1. Starr, T.F. Pultrusion for Engineers; Woodhead Publishing: Cambridge, UK, 2000.

2. Vedernikov, A.; Safonov, A.; Tucci, F.; Carlone, P.; Akhatov, I. Pultruded Materials and Structures: A Review. J. Compos. Mater. 2020, 54, 4081-4117. [CrossRef]

3. Minchenkov, K.; Vedernikov, A.; Safonov, A.; Akhatov, I. Thermoplastic Pultrusion: A Review. Polymers 2021, 13, 180. [CrossRef]

4. Zhu, R.; Li, F.; Zhao, Z.; Zhang, D.; Chen, Y. Compression Behavior of Square Pyramid Substructure of Novel Pultruded FRP-Aluminum Space Truss. J. Compos. Constr. 2020, 24. [CrossRef]

5. Shekarchi, M.; Yekrangnia, M.; Biniaz, A.; Raftery, G.M. Effect of Elevated Temperatures on the Compressive Behavior of Timber Filled Steel and Pultruded GFRP Tubes. Compos. Struct. 2021, 271, 114135. [CrossRef]

6. Tucci, F.; Vedernikov, A. Design Criteria for Pultruded Structural Elements. In Reference Module in Materials Science and Materials Engineering; Elsevier: Amsterdam, The Netherlands, 2021. [CrossRef]

7. Madenci, E.; Özkılıç, Y.O.; Gemi, L. Buckling and Free Vibration Analyses of Pultruded GFRP Laminated Composites: Experimental, Numerical and Analytical Investigations. Compos. Struct. 2020, 254, 112806. [CrossRef]

8. Gemi, L.; Madenci, E.; Özkılıç, Y.O. Experimental, Analytical and Numerical Investigation of Pultruded GFRP Composite Beams Infilled with Hybrid FRP Reinforced Concrete. Eng. Struct. 2021, 244, 112790. [CrossRef]

9. Li, C.; Yin, X.; Wang, Y.; Zhang, L.; Zhang, Z.; Liu, Y.; Xian, G. Mechanical Property Evolution and Service Life Prediction of Pultruded Carbon/Glass Hybrid Rod Exposed in Harsh Oil-Well Condition. Compos. Struct. 2020, 246, 112418. [CrossRef]

10. Gao, Y.; Zhang, D.; Li, F.; Zhao, Q.; Zhao, Z.; Chen, Y. Bearing Strength and Failure Behaviour of Composite Pre-Tightened Multi-Tooth Joint. Compos. Struct. 2021, 272, 114208. [CrossRef]

11. Tinkov, D.V.; Safonov, A.A. Design Optimization of Truss Bridge Structures of Composite Materials. J. Mach. Manuf. Reliab. 2017, 46, 46-52. [CrossRef]

12. Sorina, T.G.; Safonov, A.A.; Khairetdinov, A.K. Pecularities of Using Carbon Glass-Reinforced Plastic in Pultrusion Composite Profiles for Bridge Engineering. J. Mach. Manuf. Reliab. 2010, 39, 47-51. [CrossRef] 
13. Zhu, R.; Li, F.; Chen, Y.; Li, R. A Hybrid Beam-Column Element for Direct Second-Order Nonlinear Analysis of PFRP Frame Structures. Compos. Struct. 2021, 271, 114171. [CrossRef]

14. Sharda, A.; Manalo, A.; Ferdous, W.; Bai, Y.; Nicol, L.; Mohammed, A.; Benmokrane, B. Axial Compression Behaviour of All-Composite Modular Wall System. Compos. Struct. 2021, 268, 113986. [CrossRef]

15. Toubia, E.A.; Alomari, A.; Morgan, A.B.; Klosterman, D. Influence of Heat Damage on the Bolted Double Lap Joint Strength of Pultruded E-Glass/Polyester Composites. Thin Walled Struct. 2021, 163, 107764. [CrossRef]

16. Alhawamdeh, M.; Alajarmeh, O.; Aravinthan, T.; Shelley, T.; Schubel, P.; Kemp, M.; Zeng, X. Modelling Hollow Pultruded FRP Profiles under Axial Compression: Local Buckling and Progressive Failure. Compos. Struct. 2021, 262, 113650. [CrossRef]

17. Rubino, F.; Nisticò, A.; Tucci, F.; Carlone, P. Marine Application of Fiber Reinforced Composites: A Review. J. Mar. Sci. Eng. 2020, 8, 26. [CrossRef]

18. Zyka, K.; Mohajerani, A. Composite Piles: A Review. Constr. Build. Mater. 2016, 107, 394-410. [CrossRef]

19. Madenci, E.; Özkılıç, Y.O.; Gemi, L. Experimental and Theoretical Investigation on Flexure Performance of Pultruded GFRP Composite Beams with Damage Analyses. Compos. Struct. 2020, 242, 112162. [CrossRef]

20. Struzziero, G.; Maistros, G.M.; Hartley, J.; Skordos, A.A. Materials Modelling and Process Simulation of the Pultrusion of Curved Parts. Compos. Part A Appl. Sci. Manuf. 2021, 144, 106328. [CrossRef]

21. Dubinskii, S.V.; Safonov, A.A. Composite-Friendly Approach to Certification of Advanced Materials and Fabrication Methods Used in Aviation Industry. J. Mach. Manuf. Reliab. 2017, 46, 501-506. [CrossRef]

22. Ferdous, W.; Manalo, A.; AlAjarmeh, O.; Mohammed, A.A.; Salih, C.; Yu, P.; Mehrinejad Khotbehsara, M.; Schubel, P. Static Behaviour of Glass Fibre Reinforced Novel Composite Sleepers for Mainline Railway Track. Eng. Struct. 2021, $229,111627$. [CrossRef]

23. Li, C.; Xian, G.; Li, H. Tension-Tension Fatigue Performance of a Large-Diameter Pultruded Carbon/Glass Hybrid Rod. Int. J. Fatigue 2019, 120, 141-149. [CrossRef]

24. Jeppesen, N.; Mikkelsen, L.P.; Dahl, A.B.; Nymark, A.N.; Dahl, V.A. Quantifying Effects of Manufacturing Methods on Fiber Orientation in Unidirectional Composites Using Structure Tensor Analysis. Compos. Part A Appl. Sci. Manuf. 2021, $149,106541$. [CrossRef]

25. Corrado, A.; Polini, W.; Sorrentino, L.; Bellini, C. Geometrical Deviation Analysis of CFRP Thin Laminate Assemblies: Numerical and Experimental Results. Compos. Sci. Technol. 2018, 168, 1-11. [CrossRef]

26. Hörberg, E.; Nyman, T.; Åkermo, M.; Hallström, S. Thickness Effect on Spring-in of Prepreg Composite L-Profiles-An Experimental Study. Compos. Struct. 2019, 209, 499-507. [CrossRef]

27. Wisnom, M.R.; Potter, K.D.; Ersoy, N. Shear-Lag Analysis of the Effect of Thickness on Spring-in of Curved Composites. J. Compos. Mater. 2007, 41, 1311-1324. [CrossRef]

28. Hörberg, E.; Åkermo, M.; Hallström, S. Moisture Effect on Shape Distortions of Curved Quasi-Isotropic Prepreg Composite Laminates. Compos. Part A Appl. Sci. Manuf. 2021, 145, 106361. [CrossRef]

29. Abouhamzeh, M.; Sinke, J.; Jansen, K.M.B.; Benedictus, R. Closed Form Expression for Residual Stresses and Warpage during Cure of Composite Laminates. Compos. Struct. 2015, 133, 902-910. [CrossRef]

30. Yuksel, O.; Sandberg, M.; Hattel, J.H.; Akkerman, R.; Baran, I. Mesoscale Process Modeling of a Thick Pultruded Composite with Variability in Fiber Volume Fraction. Materials 2021, 14, 3763. [CrossRef]

31. Sandberg, M.; Yuksel, O.; Baran, I.; Spangenberg, J.; Hattel, J.H. Steady-State Modelling and Analysis of Process-Induced Stress and Deformation in Thermoset Pultrusion Processes. Compos. Part B Eng. 2021, 216, 108812. [CrossRef]

32. Traiforos, N.; Turner, T.; Runeberg, P.; Fernass, D.; Chronopoulos, D.; Glock, F.; Schuhmacher, G.; Hartung, D. A Simulation Framework for Predicting Process-Induced Distortions for Precise Manufacturing of Aerospace Thermoset Composites. Compos. Struct. 2021, 114465. [CrossRef]

33. Albert, C.; Fernlund, G. Spring-in and Warpage of Angled Composite Laminates. Compos. Sci. Technol. 2002, 62, 1895-1912. [CrossRef]

34. Bapanapalli, S.K.; Smith, L.V. A Linear Finite Element Model to Predict Processing-Induced Distortion in FRP Laminates. Compos. Part A Appl. Sci. Manuf. 2005, 36, 1666-1674. [CrossRef]

35. Fernlund, G.; Rahman, N.; Courdji, R.; Bresslauer, M.; Poursartip, A.; Willden, K.; Nelson, K. Experimental and Numerical Study of the Effect of Cure Cycle, Tool Surface, Geometry, and Lay-up on the Dimensional Fidelity of Autoclave-Processed Composite Parts. Compos. Part A Appl. Sci. Manuf. 2002, 33, 341-351. [CrossRef]

36. Fernlund, G.; Osooly, A.; Poursartip, A.; Vaziri, R.; Courdji, R.; Nelson, K.; George, P.; Hendrickson, L.; Griffith, J. Finite Element Based Prediction of Process-Induced Deformation of Autoclaved Composite Structures Using 2D Process Analysis and 3D Structural Analysis. Compos. Struct. 2003, 62, 223-234. [CrossRef]

37. Svanberg, J.M.; Holmberg, J.A. An Experimental Investigation on Mechanisms for Manufacturing Induced Shape Distortions in Homogeneous and Balanced Laminates. Compos. Part A Appl. Sci. Manuf. 2001, 32, 827-838. [CrossRef]

38. Jain, L.K.; Lutton, B.G.; Mai, Y.-W.; Paton, R. Stresses and Deformations Induced during Manufacturing. Part II: A Study of the Spring-in Phenomenon. J. Compos. Mater. 1997, 31, 696-719. [CrossRef]

39. Svanberg, J.M.; Holmberg, J.A. Prediction of Shape Distortions. Part II. Experimental Validation and Analysis of Boundary Conditions. Compos. Part A Appl. Sci. Manuf. 2004, 35, 723-734. [CrossRef] 
40. Nielsen, M.W. Prediction of Process Induced Shape Distortions and Residual Stresses in Large Fibre Reinforced Composite Laminates: With Application to Wind Turbine Blades. Ph.D. Thesis, Technical University of Denmark, Lyngby, Denmark, 25 June 2013.

41. Hsiao, K.-T.; Gangireddy, S. Investigation on the Spring-in Phenomenon of Carbon Nanofiber-Glass Fiber/Polyester Composites Manufactured with Vacuum Assisted Resin Transfer Molding. Compos. Part A Appl. Sci. Manuf. 2008, 39, 834-842. [CrossRef]

42. Corrado, A.; Polini, W. Measurement of Flexible Components in Composite Material by a 3-2-1 Locating Scheme. Compos. Sci. Technol. 2020, 189, 108036. [CrossRef]

43. Sorrentino, L.; Bellini, C. Compaction Influence on Spring-in of Thin Composite Parts: Experimental and Numerical Results. J. Compos. Mater. 2015, 49, 2149-2158. [CrossRef]

44. Ding, A.; Wang, J.; Ni, A.; Li, S. A New Analytical Solution for Cure-Induced Spring-in of L-Shaped Composite Parts. Compos. Sci. Technol. 2019, 171, 1-12. [CrossRef]

45. Hou, M.; Ye, L.; Mai, Y.W. Manufacturing Process and Mechanical Properties of Thermoplastic Composite Components. J. Mater. Process. Technol. 1997, 63, 334-338. [CrossRef]

46. Ganley, J.M.; Mawi, A.K.; Huybrechts, S. Explaining Spring-In in Filament Wound Carbon Fiber/Epoxy Composites. J. Compos. Mater. 2000, 34, 1216-1239. [CrossRef]

47. Li, N.; Li, Y.; Hao, X.; Gao, J. A Comparative Experiment for the Analysis of Microwave and Thermal Process Induced Strains of Carbon Fiber/Bismaleimide Composite Materials. Compos. Sci. Technol. 2015, 106, 15-19. [CrossRef]

48. Baran, I.; Akkerman, R.; Hattel, J.H. Modelling the Pultrusion Process of an Industrial L-Shaped Composite Profile. Compos. Struct. 2014, 118, 37-48. [CrossRef]

49. Baran, I.; Tutum, C.C.; Nielsen, M.W.; Hattel, J.H. Process Induced Residual Stresses and Distortions in Pultrusion. Compos. Part B Eng. 2013, 51, 148-161. [CrossRef]

50. Wisnom, M.R.; Gigliotti, M.; Ersoy, N.; Campbell, M.; Potter, K.D. Mechanisms Generating Residual Stresses and Distortion during Manufacture of Polymer-Matrix Composite Structures. Compos. Part A Appl. Sci. Manuf. 2006, 37, 522-529. [CrossRef]

51. Radford, D.W.; Rennick, T.S. Separating Sources of Manufacturing Distortion in Laminated Composites. J. Reinf. Plast. Compos. 2000, 19, 621-641. [CrossRef]

52. Kappel, E.; Stefaniak, D.; Hühne, C. Process Distortions in Prepreg Manufacturing-An Experimental Study on CFRP L-Profiles. Compos. Struct. 2013, 106, 615-625. [CrossRef]

53. Wiersma, H.W.; Peeters, L.J.B.; Akkerman, R. Prediction of Springforward in Continuous-Fibre/Polymer L-Shaped Parts. Compos. Part A Appl. Sci. Manuf. 1998, 29, 1333-1342. [CrossRef]

54. David, A. Darrow, J.; Smith, L.V. Isolating Components of Processing Induced Warpage in Laminated Composites. J. Compos. Mater. 2002, 36, 2407-2419. [CrossRef]

55. Ersoy, N.; Garstka, T.; Potter, K.; Wisnom, M.R.; Porter, D.; Stringer, G. Modelling of the Spring-in Phenomenon in Curved Parts Made of a Thermosetting Composite. Compos. Part A Appl. Sci. Manuf. 2010, 41, 410-418. [CrossRef]

56. Svanberg, J.M.; Holmberg, J.A. Prediction of Shape Distortions Part I. FE-Implementation of a Path Dependent Constitutive Model. Compos. Part A Appl. Sci. Manuf. 2004, 35, 711-721. [CrossRef]

57. Bogetti, T.A.; Gillespie, J.W., Jr. Process-Induced Stress and Deformation in Thick-Section Thermoset Composite Laminates. J. Compos. Mater. 1992, 26, 626-660. [CrossRef]

58. Arafath, A.R.A.; Vaziri, R.; Poursartip, A. Closed-Form Solution for Process-Induced Stresses and Deformation of a Composite Part Cured on a Solid Tool: Part II—Curved Geometries. Compos. Part A Appl. Sci. Manuf. 2009, 40, 1545-1557. [CrossRef]

59. Liu, X.; Wang, X.; Guan, Z.; Jiang, T.; Geng, K.; Li, Z. Study on Cure-Induced Residual Stresses and Spring-in Deformation of L-Shaped Composite Laminates Using a Simplified Constitutive Model Considering Stress Relaxation. Compos. Struct. 2021, 272, 114203. [CrossRef]

60. Vedernikov, A.; Tucci, F.; Carlone, P.; Gusev, S.; Konev, S.; Firsov, D.; Akhatov, I.; Safonov, A. Effects of Pulling Speed on Structural Performance of L-Shaped Pultruded Profiles. Compos. Struct. 2021, 255, 112967. [CrossRef]

61. Safonov, A.A.; Carlone, P.; Akhatov, I. Mathematical Simulation of Pultrusion Processes: A Review. Compos. Struct. 2018, 184, 153-177. [CrossRef]

62. Struzziero, G.; Teuwen, J.J.E.; Skordos, A.A. Numerical Optimisation of Thermoset Composites Manufacturing Processes: A Review. Compos. Part A Appl. Sci. Manuf. 2019, 124, 105499. [CrossRef]

63. Vedernikov, A.; Nasonov, Y.; Korotkov, R.; Gusev, S.; Akhatov, I.; Safonov, A. Effects of Additives on the Cure Kinetics of Vinyl Ester Pultrusion Resins. J. Compos. Mater. 2021. [CrossRef]

64. Safonov, A.; Gusev, M.; Saratov, A.; Konstantinov, A.; Sergeichev, I.; Konev, S.; Gusev, S.; Akhatov, I. Modeling of Cracking during Pultrusion of Large-Size Profiles. Compos. Struct. 2020, 235, 111801. [CrossRef]

65. Sandberg, M.; Yuksel, O.; Baran, I.; Hattel, J.H.; Spangenberg, J. Numerical and Experimental Analysis of Resin-Flow, HeatTransfer, and Cure in a Resin-Injection Pultrusion Process. Compos. Part A Appl. Sci. Manuf. 2020, 143, 106231. [CrossRef]

66. Barkanov, E.; Akishin, P.; Miazza, N.L.; Galvez, S. ANSYS-Based Algorithms for a Simulation of Pultrusion Processes. Mech. Adv. Mater. Struct. 2017, 24, 377-384. [CrossRef]

67. Safonov, A.A.; Suvorova, Y.V. Optimization of the Pultrusion Process for a Rod with a Large Diameter. J. Mach. Manuf. Reliab. 2009, 38, 572-578. [CrossRef] 
68. Carlone, P.; Baran, I.; Hattel, J.H.; Palazzo, G.S. Computational Approaches for Modeling the Multiphysics in Pultrusion Process. Adv. Mech. Eng. 2013, 2013. [CrossRef]

69. Yuksel, O.; Sandberg, M.; Baran, I.; Ersoy, N.; Hattel, J.H.; Akkerman, R. Material Characterization of a Pultrusion Specific and Highly Reactive Polyurethane Resin System: Elastic Modulus, Rheology, and Reaction Kinetics. Compos. Part B Eng. 2020, 207, 108543. [CrossRef]

70. Wang, J.; Kelly, D.; Hillier, W. Finite Element Analysis of Temperature Induced Stresses and Deformations of Polymer Composite Components. J. Compos. Mater. 2000, 34, 1456-1471. [CrossRef]

71. Jain, L.K.; Mai, Y.-W. Stresses and Deformations Induced during Manufacturing. Part I: Theoretical Analysis of Composite Cylinders and Shells. J. Compos. Mater. 1997, 31, 672-695. [CrossRef]

72. Ersoy, N.; Potter, K.; Wisnom, M.R.; Clegg, M.J. Development of Spring-in Angle during Cure of a Thermosetting Composite. Compos. Part A Appl. Sci. Manuf. 2005, 36, 1700-1706. [CrossRef]

73. Ruiz, E.; Trochu, F. Multi-Criteria Thermal Optimization in Liquid Composite Molding to Reduce Processing Stresses and Cycle Time. Compos. Part A Appl. Sci. Manuf. 2006, 37, 913-924. [CrossRef]

74. Kravchenko, O.G.; Kravchenko, S.G.; Pipes, R.B. Chemical and Thermal Shrinkage in Thermosetting Prepreg. Compos. Part A Appl. Sci. Manuf. 2016, 80, 72-81. [CrossRef]

75. Takagaki, K.; Minakuchi, S.; Takeda, N. Process-Induced Strain and Distortion in Curved Composites. Part I: Development of Fiber-Optic Strain Monitoring Technique and Analytical Methods. Compos. Part A Appl. Sci. Manuf. 2017, 103, 236-251. [CrossRef]

76. Nawab, Y.; Sonnenfeld, C.; Saouab, A.; Agogué, R.; Beauchêne, P. Characterisation and Modelling of Thermal Expansion Coefficient of Woven Carbon/Epoxy Composite and Its Application to the Determination of Spring-In. J. Compos. Mater. 2017, 51, 1527-1538. [CrossRef]

77. Hu, H.; Li, S.; Wang, J.; Zu, L.; Cao, D.; Zhong, Y. Monitoring the Gelation and Effective Chemical Shrinkage of Composite Curing Process with a Novel FBG Approach. Compos. Struct. 2017, 176, 187-194. [CrossRef]

78. Exner, W.; Hein, R.; Mahrholz, T.; Wierach, P.; Monner, H.P.; Sinapius, M. Impact of Nanoparticles on the Process-Induced Distortions of Carbon Fiber Reinforced Plastics: An Experimental and Simulative Approach. J. Appl. Polym. Sci. 2019, $136,47031$. [CrossRef]

79. Groh, F.; Kappel, E.; Hühne, C.; Brymerski, W. Investigation of Fast Curing Epoxy Resins Regarding Process Induced Distortions of Fibre Reinforced Composites. Compos. Struct. 2019, 207, 923-934. [CrossRef]

80. Qiao, W.; Yao, W. Modelling of Process-Induced Deformation for Composite Parts Considering Tool-Part Interaction. Materials 2020, 13, 4503. [CrossRef]

81. Shaker, K.; Nawab, Y.; Saouab, A. Experimental and Numerical Investigation of Reduction in Shape Distortion for Angled Composite Parts. Int. J. Mater. Form. 2020, 13, 897-906. [CrossRef]

82. Struzziero, G.; Nardi, D.; Sinke, J.; Teuwen, J. Cure-Induced Residual Stresses for Warpage Reduction in Thermoset Laminates. J. Compos. Mater. 2020, 54, 3055-3065. [CrossRef]

83. Vedernikov, A.N.; Safonov, A.A.; Gusev, S.A.; Carlone, P.; Tucci, F.; Akhatov, I.S. Spring-in Experimental Evaluation of L-Shaped Pultruded Profiles. IOP Conf. Ser. Mater. Sci. Eng. 2020, 747, 012013. [CrossRef]

84. Vedernikov, A.; Tucci, F.; Safonov, A.; Carlone, P.; Gusev, S.; Akhatov, I. Investigation on the Shape Distortions of Pultruded Profiles at Different Pulling Speed. Procedia Manuf. 2020, 47, 1-5. [CrossRef]

85. Zocher, M.A.; Groves, S.E.; Allen, D.H. A Three-Dimensional Finite Element Formulation for Thermoviscoelastic Orthotropic Media. Int. J. Numer. Methods Eng. 1997, 40, 2267-2288. [CrossRef]

86. White, S.R.; Kim, Y.K. Process-Induced Residual Stress Analysis of AS4/3501-6 Composite Material. Mech. Compos. Mater. Struct. 1998, 5, 153-186. [CrossRef]

87. Hill, R. A Self-Consistent Mechanics of Composite Materials. J. Mech. Phys. Solids 1965, 13, 213-222. [CrossRef]

88. Batch, G.L.; Macosko, C.W. Heat Transfer and Cure in Pultrusion: Model and Experimental Verification. AIChE J. 1993, 39, 1228-1241. [CrossRef]

89. Baran, I.; Hattel, J.H.; Akkerman, R.; Tutum, C.C. Mechanical Modelling of Pultrusion Process: 2D and 3D Numerical Approaches. Appl. Compos. Mater. 2014, 22, 99-118. [CrossRef]

90. Nasonov, Y.; Safonov, A.; Gusev, S.; Akhatov, I. Mathematical Simulation the Kinetics of Polymerization of Vinyl Ester Resin Using in Pultrusion. IOP Conf. Ser. Mater. Sci. Eng. 2020, 747, 12010. [CrossRef]

91. Johnston, A.A. An Integrated Model of the Development of Process-Induced Deformation in Autoclave Processing of Composite Structures. Ph.D. Thesis, The University of British Columbia, Vancouver, BC, Canada, May 1997.

92. Khoun, L.; Centea, T.; Hubert, P. Characterization Methodology of Thermoset Resins for the Processing of Composite MaterialsCase Study: CYCOM 890RTM Epoxy Resin. J. Compos. Mater. 2010, 44, 1397-1415. [CrossRef]

93. O'Brien, D.J.; White, S.R. Cure Kinetics, Gelation, and Glass Transition of a Bisphenol F Epoxide. Polym. Eng. Sci. 2003, 43, 863-874. [CrossRef]

94. Plepys, A.R.; Farris, R.J. Evolution of Residual Stresses in Three-Dimensionally Constrained Epoxy Resins. Polymer 1990, 31, 1932-1936. [CrossRef]

95. Abaqus Analysis User Manual, Version 6.14. 2014. Available online: https://www.3ds.com/products-services. (accessed on 1 June 2021) 
96. ISO 6721-1:2011. Plastics—Determination of Dynamic Mechanical Properties—Part 1: General Principles; International Organization for Standardization: Geneva, Switzerland, 2011.

97. ISO 11357-4:2005. Plastics_Differential Scanning Calorimetry (DSC)_Part 4: Determination of Specific Heat Capacity; International Organization for Standardization: Geneva, Switzerland, 2005.

98. ISO 22007-4:2008. Plastics—Determination of Thermal Conductivity and Thermal Diffusivity—Part 4: Laser Flash Method; International Organization for Standardization: Geneva, Switzerland, 2008.

99. ISO 11359-2:1999. Plastics_-Thermomechanical Analysis (TMA)—Part 2: Determination of Coefficient of Linear Thermal Expansion and Glass Transition Temperature; International Organization for Standardization: Geneva, Switzerland, 1999.

100. Baran, I. Pultrusion: State-of-the-Art Process. Models. Smithers Rapra: Shropshire, UK, 2015.

101. Chachad, Y.R.; Roux, J.A.; Vaughan, J.G.; Arafat, E. Three-Dimensional Characterization of Pultruded Fiberglass-Epoxy Composite Materials. J. Reinf. Plast. Compos. 1995, 14, 495-512. [CrossRef]

102. Akkerman, R. On the Properties of Quasi-Isotropic Laminates. Compos. Part B Eng. 2002, 33, 133-140. [CrossRef]

103. Mahrholz, T.; Stängle, J.; Sinapius, M. Quantitation of the Reinforcement Effect of Silica Nanoparticles in Epoxy Resins Used in Liquid Composite Moulding Processes. Compos. Part A Appl. Sci. Manuf. 2009, 40, 235-243. [CrossRef]

104. Haider, M.; Hubert, P.; Lessard, L. Cure Shrinkage Characterization and Modeling of a Polyester Resin Containing Low Profile Additives. Compos. Part A Appl. Sci. Manuf. 2007, 38, 994-1009. [CrossRef]

105. Methven, J.M.; Ghaffariyan, S.R.; Abidin, A.Z. Manufacture of Fiber-Reinforced Composites by Microwave Assisted Pultrusion. Polym. Compos. 2000, 21, 586-594. [CrossRef]

106. Struzziero, G.; Teuwen, J.J.E. A Fully Coupled Thermo-Mechanical Analysis for the Minimisation of Spring-in and Process Time in Ultra-Thick Components for Wind Turbine Blades. Compos. Part A Appl. Sci. Manuf. 2020, 139. [CrossRef]

107. Liu, T.; Vieira, J.D.; Harries, K.A. Predicting Flange Local Buckling Capacity of Pultruded GFRP I-Sections Subject to Flexure. J. Compos. Constr. 2020, 24. [CrossRef]

108. Wu, C.; Zhang, L.-T.; Tam, L.; Yan, L.; He, L. Effect of Bearing Length on Web Crippling Behavior of Pultruded GFRP Channel Section. Compos. Struct. 2020, 253, 112810. [CrossRef]

109. Civera, M.; Boscato, G.; Zanotti Fragonara, L. Treed Gaussian Process for Manufacturing Imperfection Identification of Pultruded GFRP Thin-Walled Profile. Compos. Struct. 2020, 254, 112882. [CrossRef]

110. Safonov, A.A. 3D Topology Optimization of Continuous Fiber-Reinforced Structures via Natural Evolution Method. Compos. Struct. 2019, 215, 289-297. [CrossRef]

111. Poveda, R.; Gupta, N.; Porfiri, M. Poisson's Ratio of Hollow Particle Filled Composites. Mater. Lett. 2010, 64, 2360-2362. [CrossRef] 